\title{
3D CT stereoscopic imaging: an improved anatomical understanding of the anterior ethmoid sinus and frontal sinus drainage pathway*
}

\author{
S.J. Zinreich'1, F.A. Kuhn², N.R. London Jr.', D. Kennedy"4, M. Solaiyappan', \\ W. Hosemann 5
}

Rhinology Online, Vol 3: 202 - 220, 2020 http://doi.org/10.4193/RHINOL/20.061

\author{
*Received for publication: \\ September 16, 2020
}

2 The Georgia Nasal and Sinus Institute Savannah, GA, USA

${ }^{3}$ The Department of Otorhinolaryngology Head and Neck Surgery, The Johns Hopkins Medical Institutions, Baltimore, MD, USA Accepted: November 20,2020
${ }^{4}$ The Department of Otorhinolaryngology Head and Neck Surgery, the Perelman School of Medicine University of Pennsylvania, Published: November 26,2020 Philadelphia, PA, USA

${ }^{5}$ Department of General Otorhinolaryngology-Head and Neck Surgery, University of Greifswald, Germany

\begin{abstract}
Objective: The objective of this presentation is to display a series of new anatomical concepts and terms regarding the frontal sinus, its drainage pathway and cells vs. spaces of the anterior ethmoid, based on Three-Dimensional Computer X-ray Tomography Stereoscopic Imaging (3DCTSI) and contrast these concepts to those reported in the current literature.
\end{abstract}

Methods: Given the new anatomic observations provided by 3DCTSI, and the widespread anatomic variations a small sample was initially selected to describe our observations. Six exemplary cases according to the "Classification of Fronto-Ethmoidal cells" by Kuhn, Bent et al., Lee et al., expanded by Wormald et al., and adopted by Ramakrishnan et al., Huang et al., and Void et al. ${ }^{(1-7)}$ were chosen to illustrate our detailed anatomic observations. Additional observations and data of prevalence identified in a larger series will follow.

Results and Conclusion: Conceptually, the anterior ethmoid "cells" are in essence "spaces" with openings that communicate with the middle meatus and/or the ethmoidal infundibulum. The frontal sinus and frontal recess are a united and continuous three-dimensional, irregularly shaped space, the Frontal Sinus/Recess Space (FSRS). The uncinate process has two segments: the Ethmoidal Uncinate Process (EUP), which encompasses the Infundibular Space of the EUP (IS-EUP), currently known as the Agger Nasi cell; and the Turbinal Uncinate Process (TUP), which borders the Turbinal Infundibulum (TI) medially. The superior attachment of the EUP will be detailed in each of the six cases (Table 2). The middle meatus and infundibular passages are the drainage pathways from the frontal sinus and maxillary sinus to the nasal cavity.

Key words: frontal sinus, frontal recess, frontal sinus drainage pathway, uncinate process, infundibulum, ethmoid, 3D CT stereoscopic imaging

\section{Introduction}

The introduction of Endoscopic Sinus Surgery (ESS) was aided by the improved imaging of X-ray polytomography, which was then replaced by planar X-ray Computed Tomography (CT) in $1985^{(8,9)}$. In the late 1980s, the introduction of CT Multiplanar Reconstruction, advanced Functional Endoscopic Surgery and Image-Guided Surgery improved our understanding of the de- tailed sinus anatomy (Figure 1) ${ }^{(8-13)}$. Observations of the anatomical subunits, introduced in the late $1800 \mathrm{~s}^{(14-22)}$, and the movement towards less invasive, "precision surgery", and highlight the importance of continuing to improve our anatomic knowledge of the Frontal Sinus Drainage Pathway, as well as, most recently the posterior ethmoid and sphenoid sinus anatomy ${ }^{(23-55)}$. 


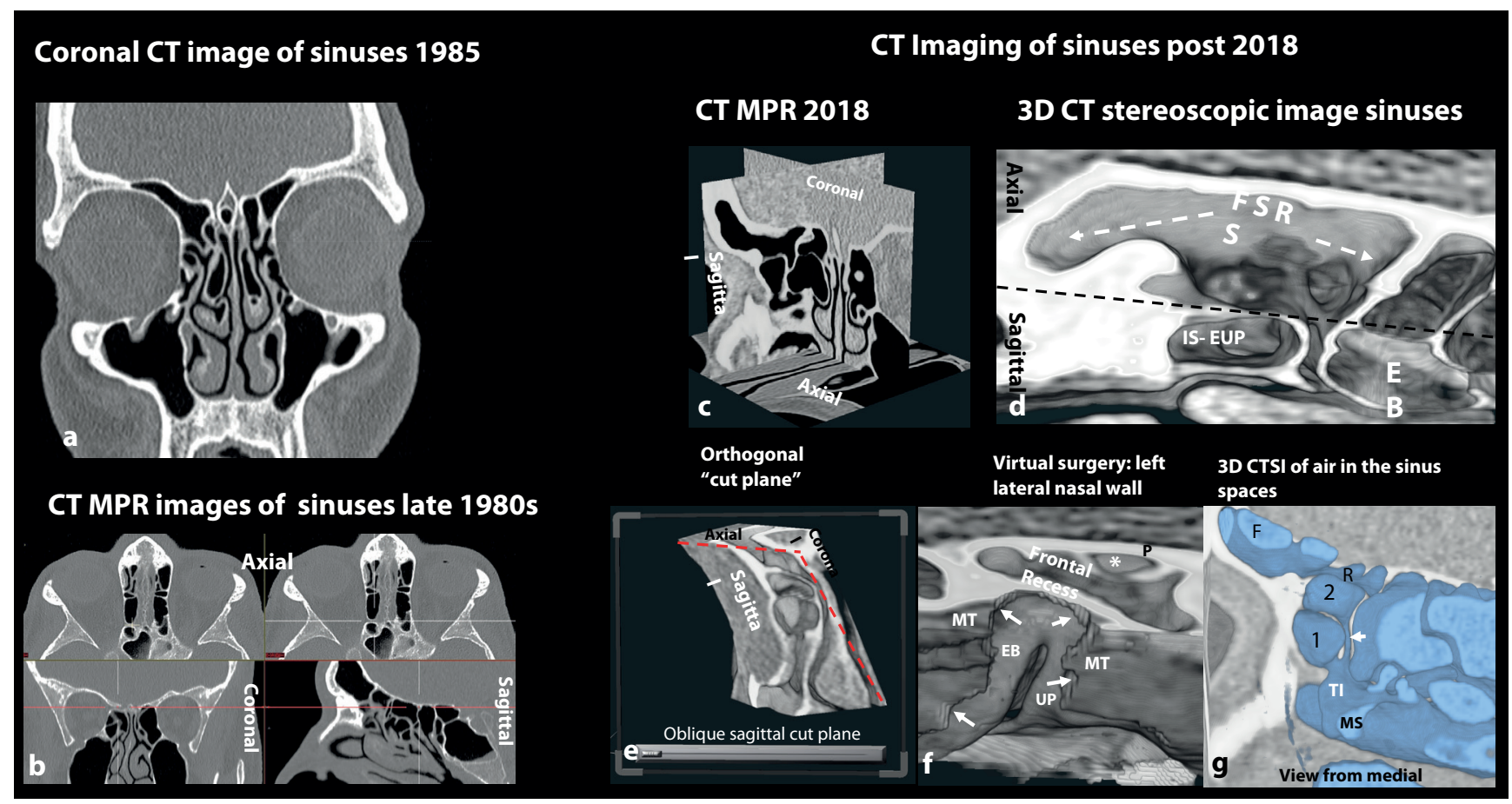

Figure 1. Evolution of $C T$ imaging of the nasal cavity and paranasal sinuses in the past three decades. (a), is a coronal plane $C T$ introduced in the mid1980s (4mm thick slices), which replaced X-ray poly-tomography for the evaluation of the sinuses; (b) is the next step - CT multiplanar reconstructions (MPR), with $2 \mathrm{~mm}$ slice thickness, simultaneously showing axial, coronal, and sagittal images; (c) a more recent advance, simultaneously displaying coronal, sagittal, and axial planes, intersecting at a shared focal point of interest within the imaged volume. Note the plane identifiers: axial, coronal and sagittal; (d) is an oblique 3DCTSI image displaying a "life-like" picture of the anterior ethmoid anatomy. The black dashed line separates the axial plane above and the sagittal plane below the dashed line;(e) shows the use of a cut plane which can be angled in any plane to reveal anatomy which cannot be revealed in the standard orthogonal views (here an oblique sagittal cut plane); (f) shows the application of virtual surgery(arrows) , partially removing the middle turbinate(MT), improving visualization of the 3D extension of the ethmoid bulla(EB), and uncinate lamella(UP, *), and their relationship to the frontal recess and lamina papyracea(P); $(\mathrm{g})$ reveals the 3D appearance of the air within the spaces within the anterior ethmoid sinus, the frontal sinus/recess space and maxillary sinus: FSRS, the frontal sinus/recess space; IS-EUP, the infundibular space of the ethmoid uncinate process; $E B$, the ethmoid bulla; Infundibular spaces within the ethmoidal Infundibulum(1,2); $F$, frontal sinus; $R$, frontal recess; T,I turbinal Infundibulum; and MS, maxillary sinus.

The perceived complexity and variability of this region largely stems from the limitations of endoscopic visualization and 2-dimensional tri-planar CT imaging ${ }^{(23-48,54,55)}$. In the past two decades, the potential advantages of 3D imaging techniques were addressed, but without the necessary depth perception, and manageability to achieve the needed displays of the regional anatomy ${ }^{(49-53)}$. A new perspective is provided by the evolving Three-Dimensional CT Stereoscopic Imaging (3DCTSI) technology, which combines volume rendering with depth perception ${ }^{(56,57)}$. Furthermore, it can be used as a virtual surgical tool for selective removal of structures in the imaging volume, which simulates a surgical dissection, enhancing surgical planning, and improved understanding of the frontal sinus outflow tract and anterior ethmoid spaces, paving the way for innovative surgical approaches.

In this study, we will present six examples according to the previously published "Classifications of Fronto-Ethmoidal cells"
(1-7) and describe the frontoethmoidal communicating passage(s) with the anterior ethmoid sinus. More particularly, we will demonstrate the following anatomical concepts and terms illuminated by 3-DCTSI:

1. The concept of cells vs. spaces

2. The frontal sinus and frontal recess as a united space

3. The frontal sinus drainage pathway

4. The attachment of the superior Ethmoid Uncinate segment in the six cases demonstrated (Table 2).

5. The two-part segments of the uncinate process 5. The multiple spaces of the infundibulum

\section{Materials and methods}

Imaging instrumentation

Axial sinus CT scans were performed on a Siemens CT scanner using a $0.7 \mathrm{~mm}$ thickness without administering intravenous contrast. 


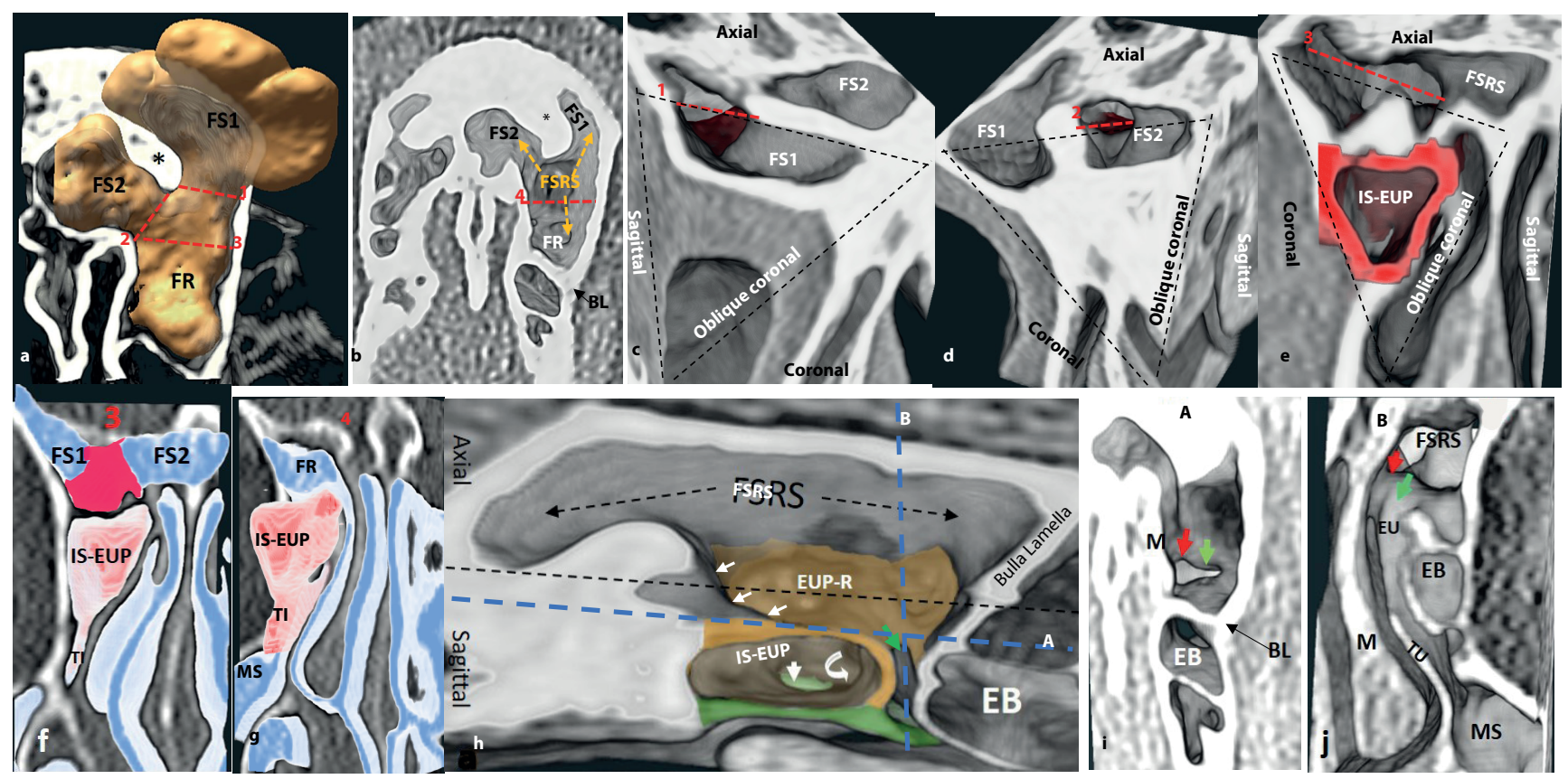

Figure 2. 3DCTSI reveals the irregular volume of the combined frontal sinus and frontal recess spaces (FSRS). (a) is a 3DCTSI image revealing the perimeter of the combined volume of the FS1\&2 spaces, which are separated by a bony ridge $\left({ }^{*}\right)$, and the Frontal Recess space (FR). (b) shows the floor of the Frontal Sinus/Recess Space (FSRS), viewed in the axial plane from above. Note the bony ridge ${ }^{*}$ ) extending from the anterior frontal bone into the floor of the frontal sinus, creating the separation between spaces FS1 and FS2 without infringing on the continuity and communication with the Frontal Recess (FR). Note that in both figs. $(a, b)$ there is no identifiable anatomic separation between the frontal sinus and the frontal recess: Bulla Lamella (BL). Figures ( $\mathrm{c}-\mathrm{e}$ ) are oblique coronal views as indicated by the black dashed triangles, revealing the planes of communication between FS1/ FS2 and FR (c,d)) as well as the combined plane of communication (e). The plane of the openings of FS1/FS2/and combined FS1\&2 are outlined with dashed red lines 1, 2, 3 on the corresponding oblique coronal views as well as the 3DSI image of the combined airspace FSRS in (a). (f) is a 3D coronal view showing the pane of coalescence between the FS (FS1 and FS2) before combining with FR (red colored outline, coronal plane 3 in (a)). (g) is a coronal 3DCTSI just posterior to coronal plane 3 , showing the reduced caliber of the FR.

An advanced evolution of the Dextroscope imaging device was used to create 3D CT Stereoscopic Imaging displays (3DCTSI) (56,57). The device provides an "en bloc" 3D display of the imaging data, which can be manipulated to display the information from any plane or direction. A "cut-away" planar view can be shifted into any angled plane to "cut" into the image volume and reveal the anatomy from any orthogonal or oblique plane. The device has a "virtual surgery" capability that can remove structures which obstruct the visualization of specific anatomic detail. Furthermore, it has a "replace function" to restore inadvertently removed anatomy. Furthermore, a 3D display of the air within the frontal/ethmoid spaces may be extracted or superimposed on the bony anatomy of the sinuses (Figure 1).

The 3DCTSI created by the Dextroscope imaging device are displayed on a stereoscopic monitor and are viewed with 3D electronic glasses. The stereoscopic display provides depth perception showing a structure, just as it would appear in nature. The challenge is to display the 3D stereoscopic formatted image on a "flat" surface. In this case only a "partially simulated" depth perception is retained. An alternative ("poor man's") 3D stereo- scopic display is available with the unit's anaglyph 3D. Here, a left/right pair of images are created in a specific colour pair combination. with red/green or red/cyan, so that left-eye image is printed in a red colour, and the right-eye image is printed using a green or cyan colour. The colour printed hard copy, when viewed using corresponding colour filter glasses, will create a binocular pair separation effect, allowing binocular vision necessary for 3D perception/stereoscopic perception.

\section{Source of information}

Six examples were selected to illustrate the "Agger nasi Cell" and the 4 types of frontal cells previously reported in the "Classification of Fronto-Ethmoidal Cells" to describe our observations ${ }^{(1-7)}$. Our evaluation includes: the frontal sinus, and the frontal recess outline; the bony architecture of the uncinate process; the relationship of these structures to the bulla lamella, the middle meatus and infundibulum; as well as the superior attachment of the Ethmoidal Uncinate Process segment (EUP).

\section{Results based on anatomic observations}

The concept of "cells" vs. "spaces" 

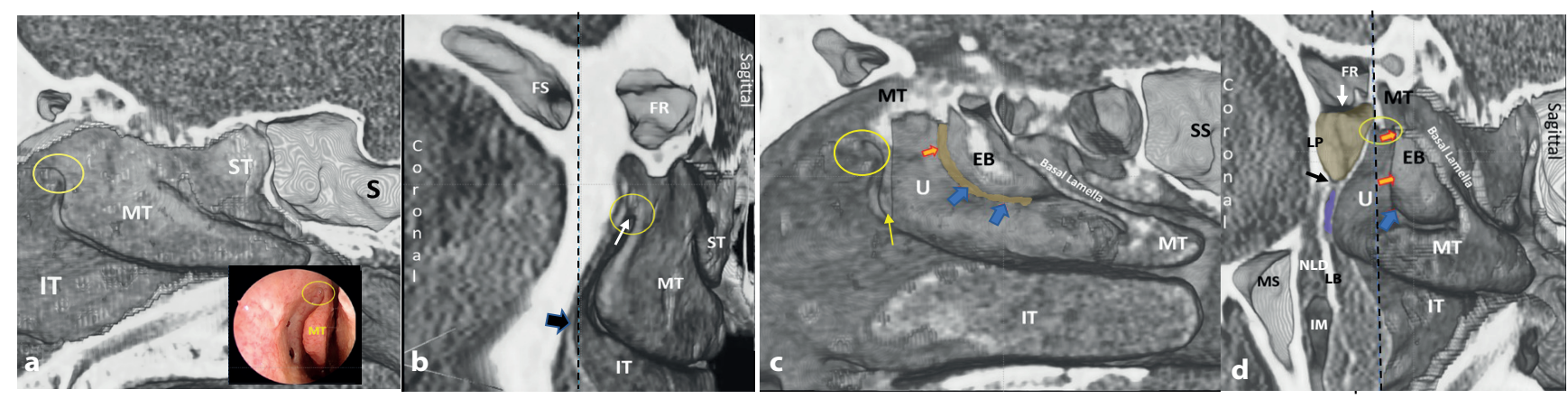

Figure 3. 3DCTSI display of the lateral nasal wall, status post septoplasty, partial middle turbinectomy, and location of the uncinate process. In (a), a sagittal display of the lateral nasal wall post "virtual" septectomy, reveals the inferior turbinate (IT), middle turbinate (MT), superior turbinate (ST), and the right sphenoid sinus (S). Note the location of the axilla (yellow circle) on this and the following images, as well as on the corresponding inset endoscopic image. In (b), an oblique anterior view with the coronal plane to the left of the black dashed line and the sagittal plane to the right of the line, provides an anterior view of the "axilla," middle turbinate attachment to the Agger Nasi region, as well as the ventral attachment of the middle turbinate (MT) to the uncinate process (white arrow). Note the superiorly extending inferior turbinate fibers (black arrow) fusing with the uncinate process fibers. In (c), a sagittal view of the lateral nasal wall post "virtual" partial middle turbinectomy (MT), showing superior fusion of the uncinate process $(U)$ with the middle turbinate (MT). A remnant of the anterior MT left in place (yellow arrow) for reference. Note the sickle shape outline of the dorsal uncinate process (red outlined orange-coloured arrow), and the hiatus semilunaris (beige color); segment of the turbinal infundibulum (blue arrows); ethmoid bulla (EB); the basal lamella; the inferior turbinate (IT); and the sphenoid sinus (SS). In (d), an oblique, anterior angled coronal view to the left of the black dashed line, and a sagittal view to the right of the black dashed line, status post septoplasty and partial middle turbinectomy, with removal of tissue volume in the coronal plane just anterior to the frontal process of the maxilla. Note the uncinate process (U), fusing with the middle turbinate at the axilla, and its superior-lateral extension to fuse with the lamina papyracea (white arrow), creating the roof of the IS-EUP (light gold colour). It also fuses inferiorly with the lamina papyracea, and lacrimal bone (LP, black arrow). Turbinal Infundibulum (blue color); maxillary sinus (MS); inferior meatus (IM); nasolacrimal duct (NLD); and lacrimal bone (LB).

Traditional anatomical concepts of ethmoidal "cells" are an oversimplification of the actual situation. We found that the anterior ethmoidal anatomy is composed of enclosed spaces, which lack ostia in the traditional sense ('a mouthlike opening in a bodily part'). We found, in all six cases" round/oval/slit-like, single or multiple openings that enable intercommunication between the spaces, with direct communication to the middle meatus and/or the infundibular passages, providing air exchange and mucociliary flow (Figures 2-12).

The frontal sinus drainage pathway shown in examples relating to "fronto-ethmoidal cells classification systems"

\section{The "Agger Nasi Cell"}

The frontal sinus/recess space (FSRS) - The fronto-ethmoidal transition region:

3DCTSI, reveals that the frontal sinus and the frontal recess spaces are continuous and unite completely, without an exactly definable anatomic landmark, which distinguishes the separation between these two spaces (Figures $2 \mathrm{a}-\mathrm{e}, \mathrm{h}$ ). Both spaces, the Frontal Sinus and the Frontal Recess, appear to be two compartments of a single space. It has often been noted that bony ridges are present within the perimeter of the frontal sinus, which, if included in the sagittal CT plane, would appear as an "hourglass"- like narrowing. However, this is not the case when the anatomy is observed with 3DCTSI in the axial perspective from above, in which the spatial volume can be observed in its entirety (Figures $2 \mathrm{a}, \mathrm{b}$ ). In this case, the bony ridge present in the floor of the frontal sinus splits the volume of the frontal sinus into two separate compartments. Each compartment, and jointly, having its communication with the frontal recess (Figures $2 \mathrm{a}, \mathrm{b}$ ). At the coronal plane where both openings have a joint communication with the frontal recess, there is a distinct concentric narrowing between frontal sinus and frontal recess spaces. The location of this coronal plane is undefined by specific anatomic landmarks and variations are seen from case to case.

Consequently, we refer to this three-dimensional cuboidal space (Figure 2 a), as the Frontal Sinus/Recess Space (FSRS). The FSRS is bordered antero-superiorly by the frontal bone, the skull base; laterally by the lamina papyracea and parts of the lacrimal bone; medially by the middle turbinate/middle meatus; and posteriorly by the bulla lamella, an extension of the uncinate lamella, or the fusion of uncinate and bulla lamellae known as the common lamella.

In the configuration, we refer to as the "Agger Nasi Cell" (ANC) the superior portion of the uncinate process extends laterally creating a "horizontal shelf", which fuses with the lamina papyracea. It extends: anteriorly to fuse with the Nasal Process of the 

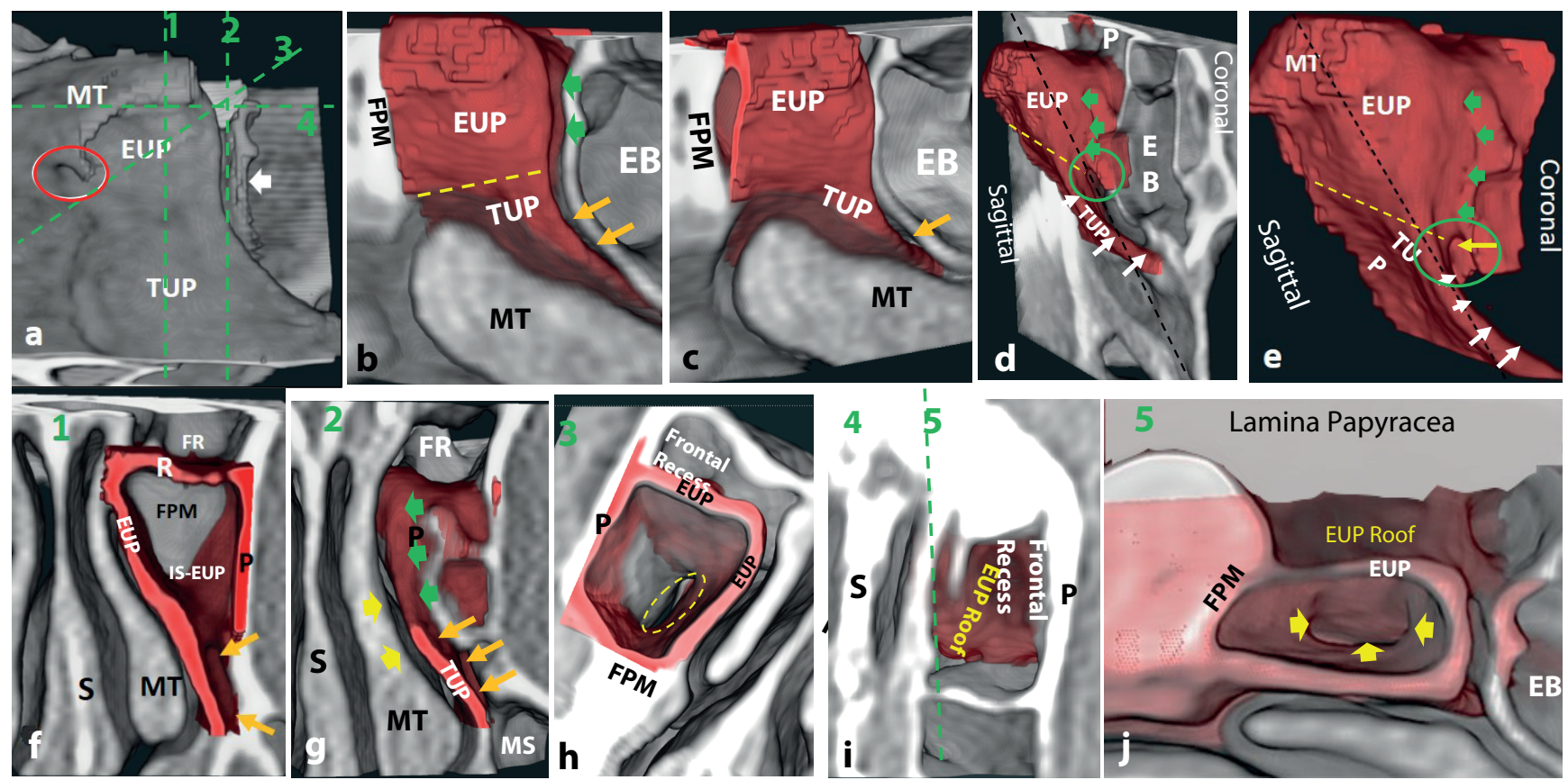

Figure 4. Segmentation of the IS-EUP currently classified as an "Agger Nasi Cell". (a) An isolated "block" of imaging data. The septum and most of the middle turbinate are removed. There has been partial removal of the postero-medial ethmoid bulla, frontal sinus and superior frontal recess. Structures are labeled as: middle turbinate (MM); ethmoid uncinate process (EUP); turbinal uncinate process (TUP); the location of "axilla" white oval; and bulla lamella (white arrow). The uncinate process and its two components, the Ethmoidal Uncinate Process (EUP), and the Turbinal Uncinate Process (TUP) were segmented "en-block", from the image data volume in (a). They are coloured red and presented in a sagittal plane viewed from medially in (b, c), as the entire Uncinate Process resides in its actual anatomic position. (d, e) show it, from a posterior view. The sagittal plane is to the left and coronal plane to the right of the black dashed line. (d) shows the segmented Uncinate Process as it is imbedded in its actual anatomic position. In both ( $d, e)$ note the plane of separation between the EUP and TUP (yellow dashed line), as well as the communication between the Ethmoid Infundibulum (green arrows), Turbinal Infundibulum (white arrows), and the Infundibular space of the Ethmoid Uncinate Process(yellow arrow), all within the green oval. Also note that the superior EUP "turns" laterally to fuse with the lamina papyracea (P) to create the roof of the EUP and the floor of the frontal recess. (f) a coronal plane viewed from posteriorly (plane \#1 in a.), showing the anterior attachment of the medial EUP to the medial border of the Frontal Process Maxilla (FPM), and its roof (R) extending along the suture between the Frontal Bone superiorly, and the FPM/Nasal Bone inferiorly to create the bony ridge, the Nasal Process of the Frontal Bone (NPFB), commonly known as the "nasal beak". Note that the lamina Papyracea fuses with the lateral border of the FPM, anteriorly enclosing the IS-EUP space. (g) a coronal image (plane \#2 in a.) viewed from posteriorly shows the posterior surface of the EUP/anterior surface of the ethmoid infundibulum (green arrows); the turbinal Infundibulum ( 3 yellow arrows), the cut surface of the TUP, the maxillary sinus (MS), and the middle meatus (2 large yellow arrows). ( $h$ ) is an anteriorly obliqued axial image viewed from above, showing the depth of the IS-EUP, with the oval opening (dashed yellow oval) providing communication with the Turbinal Infundibulum. (i) is an axial image viewed from above, showing the roof of the IS-EUP which is the floor of the Frontal Recess (red surface). The image is the source of plane \#5, sagittal fig. (j), also revealing the roof of the EUP as viewed from medially. Note the medial "edge' of the EUP, as its superior edge extends laterally to fuse with the lamina papyracea, and anteriorly extending to the Nasal Process of the Frontal bone, and posteriorly to the bulla lamella.

Frontal Bone ("nasal beak"); and extends posteriorly to fuse with the bulla lamella. The "horizontal shelf", which is the roof of the space contained within the Ethmoid Uncinate Process (EUP) and is also the floor of the Frontal Recess (FR) (Figures $10 \mathrm{~h}$-j).

The FSRS may have a variety of communications with the anterior ethmoid. It may communicate with the anterior ethmoid through a direct opening shared by the middle meatus and the ethmoidal infundibulum (Figures $10 \mathrm{i}, \mathrm{j}$ ). It is located in the teromedial floor of the space, just anterior to the bulla lamella (Figure 10 i) Less commonly (but not in Figure 10 i) the FSRS may communicate directly with the IS-EUP.

The uncinate process

Embryologically, a series of ethmo-turbinals form on the lateral nasal wall, above the maxillo-turbinal, which are composed to two segments. The more anterior segment, which angles ventrocranial (anterior-superior) is designated the Pars Ascendens and the posterior-inferior segment, which remains parallel to the nasal floor is designated as the Pars Descendens.

It is commonly held that the 1st Embryonic Ethmo-Turbinal (ET), shaped as a "boomerang/bent hook" or hockey stick shape ${ }^{(11)}$, 

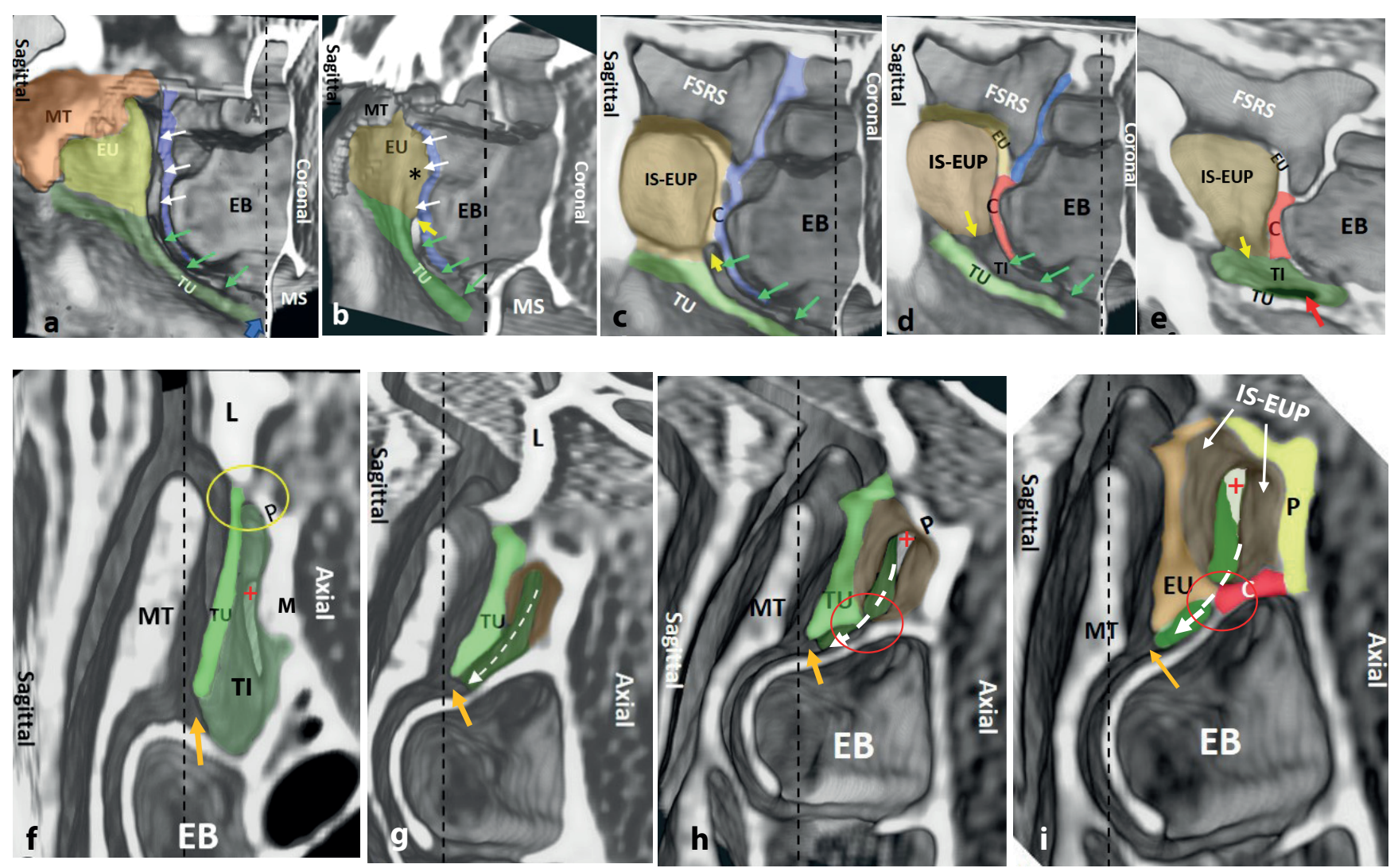

Figure 5. Three-dimensionality of the two-component uncinate process: from the sagittal and axial perspective. The sagittal perspective: In (a-e) oblique sagittal displayed images, with the sagittal plane to the left of the black dashed line, and the coronal display to the right of the line. (a) Reveals the partially resected middle turbinate (MT, gold color) fusing antero-superiorly with the ethmoidal uncinate process (EU, greenish gold). The outline of the EU is separated from the turbinal uncinate process (TU)(darker green). Note the relationship with the partially resected ethmoid bulla (EB), and the bulla lamella (blue outline); maxillary sinus (MS). The ethmoidal infundibulum is outlined with white arrows, and the turbinal infundibulum with green arrows; blue arrow represents the visible end of the turbinal uncinate process at the posterior fontanelle. In (b), a more pronounced angulation of the sagittal plane to the left demonstrating the fusion between the turbinal uncinate process (TU) and the ethmoidal uncinate process (EU). Note the laterally turned EU $(*)$, revealing the anterior surface of the ethmoid infundibulum (white arrows). Note the opening created at the inferior edge of the laterally turned uncinate lamella (yellow arrow) providing a communication between the ethmoidal and turbinal infundibulum, and the infundibular space of the EU (IS-EUP). In (c), similar to (a) with additional removal of medial sagittal image data, partially removing the medial wall of the ethmoidal uncinate process (EU), revealing the infundibular space within the EU (IS-EUP), and the relationship with the frontal sinus/ recess space. Note the fusion between the uncinate lamella (gold outline) and bulla lamella (blue outline) to create the common lamella (C); turbinal uncinate process (TU); turbinal infundibulum (green arrows). (d, and e) Displays the posterior plane of separation between the turbinal uncinate process (TU, light green surface) and the ethmoidal uncinate process (EU) (gold surface)/common lamella (C, red outline), and the opening between the IS-EUP and the TI ( yellow arrow); primary ostium of maxillary sinus (red arrow); turbinal infundibulum (green arrows, light green outline).

The axial perspective:

Figures (f-i): slightly obliqued 3DSI axial/sagittal images. The sagittal plane is to the left of the dashed black line and the axial plane is to the right of the line in all images. The information of interest is primarily on the axial planes viewed from above, (f) is most inferior and (i) the most superior. (f-h) Reveal the fusion of the TU (light green surface) with the lacrimal bone $(L)$ and the lamina papyracea $(P)$. The fusion between all three bony structures is within the area of the yellow oval on (f). The turbinal infundibulum (TI dark green), is the space between the TU and the lamina papyracea (P) and the medial maxillary sinus wall (M) The TI spare is enclosed anteriorly (vellow "circle") and is npen posteriorly, as it communicates with the middle meatus (orange arrow). The oval wedge-like opening in the base of the $\mathrm{Tl}(+$, anteriorly) represents the primary ostium of the maxillary sinus. More superiorly, in (h,i) note that the posterior superior ethmoidal uncinate process (EU) turns laterally to merge with the bulla lamella (red outline) and create a common lamella (red outline, C). The common lamella, in turn, fuses with the lamina papyracea (P), enclosing the infundibular space of the ethmoidal uncinate process (IS-EUP) and defines the inferior extent of the ethmoidal infundibulum best shown on sagittal fig. (b), (yellow arrow). Ethmoidal bulla (EB), middle turbinate (MT); curved dashed arrow shows the continued extension of the TI, as well as its communication with the ethmoidal infundibulum under the fusion of the EU with the common lamella fig. (i): in figs. (c, d), the primary ostium of maxillary sinus (+). 


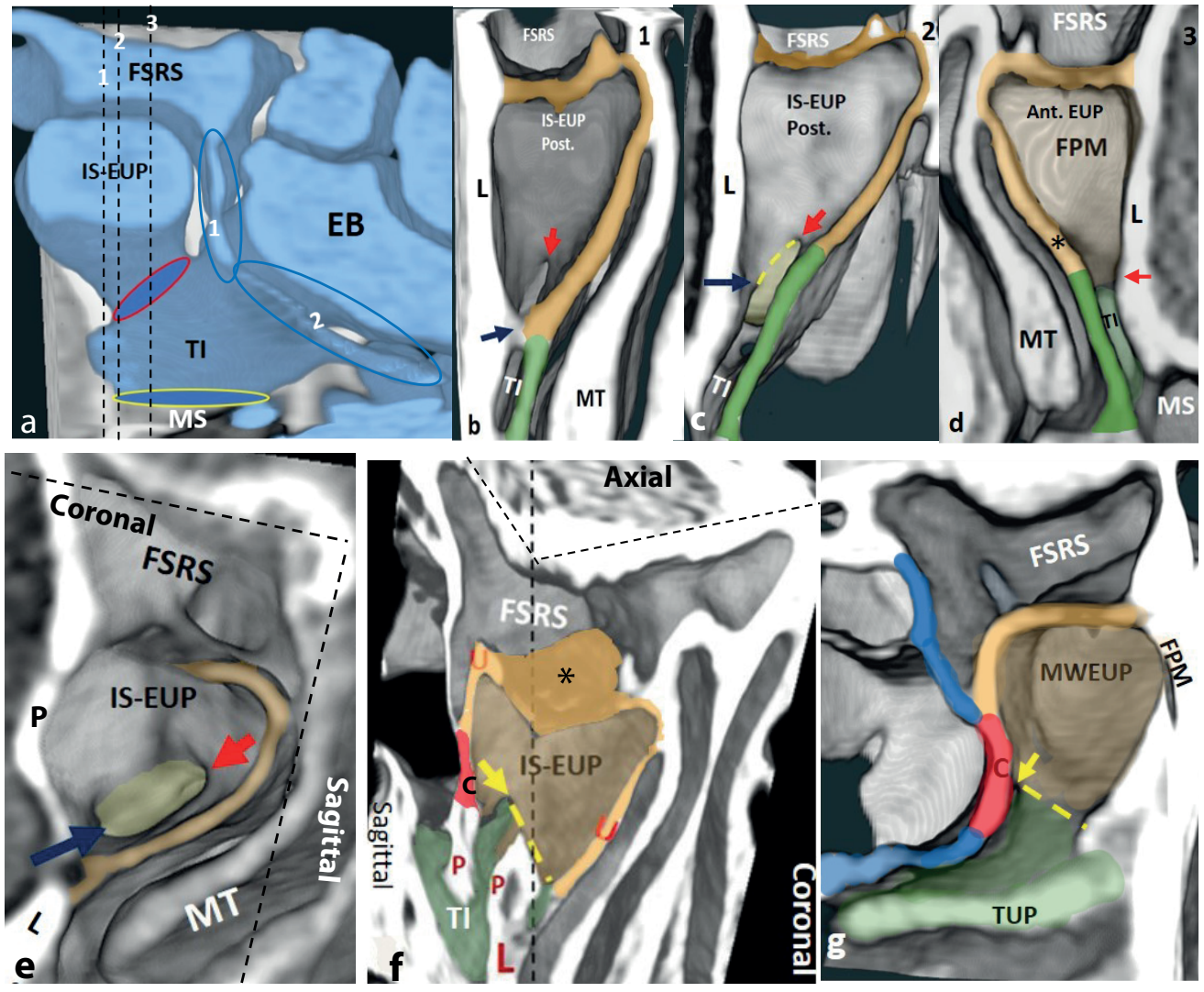

Figure 6. The plane of separation between the infundibular space of the ethmoidal uncinate process (IS-EUP) and the turbinal infundibulum (TI), and location of the opening between the IS-EUP and TI. (a) shows the three-dimensionality of air within the frontal/anterior ethmoid spaces and location of coronal planes 1-3, as demonstrated in (b-d). Note: the plane of separation between the IS-EUP and TI is also the plane of the opening, where the two spaces communicate (blue) red rimmed blue oval. This is also seen in (e) between the anterior (dark blue) and posterior (red arrows); ethmoidal infundibulum (pale blue oval, 1); posterior rim of the TI (blue oval, 2); maxillary sinus (MS); ethmoid bulla (EB). (b) is anterior to c. and (c) demonstrates the increased angulation of the TI plane and the opening between the IS-EUP and TI as it extends posteriorly. The anterior extent of the opening and its plane is at the point of fusion (dark blue arrow) between the lamina papyracea (L), and the point of separation between the superior Ethmoidal uncinate process and the inferior Turbinal uncinate process (dark blue arrow). The opening extends postero-superiorly to the inferior extent of the common lamella and the inferior ethmoidal infundibulum (red arrow in b, c \& e); ethmoid uncinate process, medial wall and roof (gold rim); turbinal Infundibulum (TI). (d), is a coronal display viewed from posterior, just anterior to the common lamella. It reveals the anterior surface of the IS-EUP, which is the frontal process of the maxilla and the junction between the gold EUP $(*)$, and the green Turbinal Uncinate (+). Note the Turbinal Infundibulum (TI), extending from the maxillary sinus (MS) up to the site of separation between the EUP and TU (red arrow). (e), is an oblique coronal/ sagittal plane. It demonstrates the light greenish shaded oval opening in the floor of the IS-EUP that provides communication with the TI; anterior and posterior margins of the opening are indicated by dark blue and red arrows, respectively; lacrimal bone (L); lamina papyracea (P). (f) oblique coronal \& sagittal planes at the anterior/lateral "corner" of the IS-EUP (gold), revealing its roof $\left(^{*}\right)$, medial border (U), posterior wall (U), the frontal recess (FSRS) extending inferiorly behind the IS-EUP and the common lamella (C, red outline): lamina papyracea (P); lacrimal bone (L); Turbinal infundibulum (TI). (g) is a sagittal image viewed from laterally. The ethmoid uncinate process and the internal medial wall of the EUP(MWEUP) are colored gold; the plane of separation between IS-EUP and TI is the dashed yellow line; the inferior ethmoid infundibulum (yellow arrow); the common lamella (C, red outline); the bulla lamella (blue outline); and the inferior attachment of the turbinal uncinate process to lamina and medial orbital wall (TUP).

regresses to form the uncinate process, with its pars ascendens believed to become the Agger Nasi Cell and the pars descendens to become the uncinate process (UP) ${ }^{(17-19)}$. Therefore, the precedent has been set for considering that these two joined segments will become dissimilar, but joined structures. They are already named differently in embryologic terms.
Schaeffer, however, demonstrated in 1916 that the 1st ET becomes the middle turbinate and that two secondary or accessory Middle Meatal Turbinals (MMT) develop "under cover of the middle turbinate."The UP develops from the first of these MMTs, and the second develops into the ethmoid bulla lamella. The two MMTs are separated by a groove, which becomes the Infundibulum and each MMT has two joined segments, a pars ascendens 

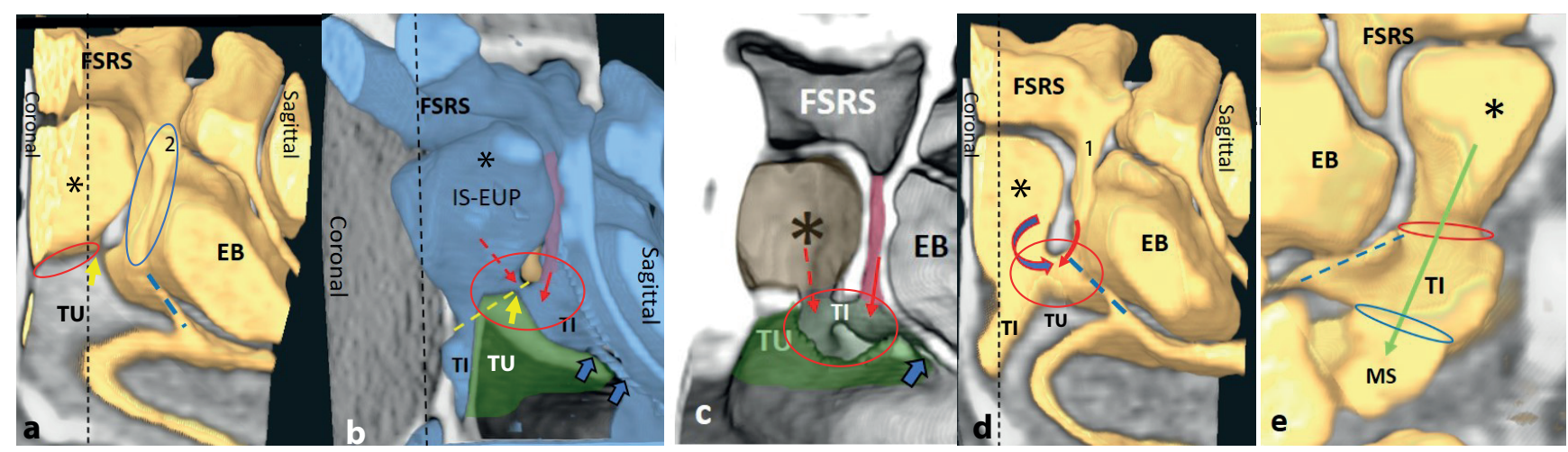

Figure 7. 3DCTSI of the air spaces within the anterior ethmoid sinus and the frontal sinus drainage pathways. (a-e) reveal the air within the anterior ethmoid spaces and the frontal sinus drainage channels, in a three-dimensional display. (a) shows an oblique coronal/ sagittal display as viewed from medially, and (e), a sagittal display as viewed from laterally. (b-d) are oblique sagittal displays with the sagittal plane to the right and the coronal plane to the left of the black dashed line, as viewed from medially. In figs. ( $a$, b) Note the relationship between the Turbinal Uncinate Process (TU) and the infundibular space of the ethmoidal uncinate process (IS-EUP, ${ }^{*}$ ), the postero-superior TU at its attachment with the EUP and its relationship to the ethmoidal infundibulum (\#1, and pink outline) and the turbinal infundibulum (TI), as it extends posteriorly (TI) (blue dashed line). The larger blue oval \#2 reveals the combined outline of the ethmoidal infundibulum and middle meatus as both extend superiorly to connect with the FSRS. The communication between the IS-EUP $\left(^{*}\right)$ and the TI is indicated by the red oval in figs. (b-d). In (d), note the three-way communication between the IS-EUP and TI (blue curved arrow), and the ethmoidal infundibulum's connection with the TI (red curved arrow). In (e), note the direct communication between the IS-EUP, the TI, and the maxillary sinus (green arrow), the primary ostium of the maxillary sinus (green oval), the ethmoidal bulla (EB), and the middle meatus (MM).

and a pars descendens ${ }^{(18)}$.

We acknowledge the continuous and joined nature of the Uncinate Process, but have chosen to name the two segments separately to clarify their origin and developmental function. Our evaluation with 3DCTSI supports Schaeffer's suggestion that the UP has two segments, with the following caveat: the pars descendens of the first MMT develops into the Turbinal Uncinate segment (TUP) and the pars ascendens becomes the Ethmoidal Uncinate segment (EUP). In Figure 3, we demonstrate the 3DCTSI appearance of the lateral nasal wall status post septectomy (Figures $3 \mathrm{a}, \mathrm{b}$ ), and the location of the uncinate process and ethmoid bulla status post virtual partial middle turbinectomy in (Figures $3 c$, d). Furthermore, in Figure 4, we show the "segmented" uncinate process, coloured in red: its relationship to the bordering anatomy, as well as the two segments of the uncinate process.

\section{The turbinal uncinate process segment (TUP)}

The infero-posterior horizontal component of the uncinate process is a planar structure, developed from the pars descendens of the first MMT, which becomes the TUP (Figures 4 a-e, 5 $\mathrm{a}-\mathrm{h}, 6 \mathrm{a}-\mathrm{g})^{(18-22)}$. It is attached anteriorly to the lacrimal bone and ascending extensions of the inferior turbinate. It is attached to the medial maxillary sinus wall and visibly extends posteriorly along the inferior turbinate to the posterior fontanelle in $80 \%$ of cases. In the remaining $20 \%$, Yoon et al. describe that TUP fibres extend further posteriorly and attach to the: inferior turbinate, lower portion of the ethmoid bulla, and the perpendicular plate of the palatine bone ${ }^{(29,30,32)}$.

Antero-superiorly, the TUP fuses with the lacrimal bone to the suture between the lacrimal bone and inferior tip of the frontal process of the maxilla (FPM) (Figures $4 \mathrm{~b}, \mathrm{c}, \mathrm{f} ; 5 \mathrm{f} ; 6 \mathrm{e}-\mathrm{g})^{(33,34)}$. This focal point is also shared with fusion of the lamina papyracea laterally and the ethmoidal uncinate process medially to the inferior tip of the FPM. This shared point of fusion between the four structures represents the anterior site of the plane of separation between the TUP and Ethmoidal Uncinate Process segment (EUP). Posteriorly this plane is angled supero-posteriorly to reach the inferior extent of the common lamella and the inferior point of the ethmoidal infundibulum. This posterior focal point also marks the superior extent of the TUP (Figures 4 e; 5 b, c, h; 6 $a, e, f)$. From this point, the TUP tapers infero-posteriorly along the antero-inferior border of the bulla lamella to visibly end at the posterior fontanelle (Figures $4 \mathrm{~d} ; 5 \mathrm{a}-\mathrm{d} ; 6 \mathrm{~g}$ ). As the TUP tapers posteriorly, it creates a space between the TUP and the medial surface of the maxillary sinus, and the lamina papyracea, the Turbinal Infundibulum (TI) earlier referred to by Schaeffer as "a pocket" (18).

\section{The ethmoidal uncinate process segment (EUP)}

From the plane of separation between the TUP and the EUP, the ethmoid segment of the uncinate process, the EUP, extends superiorly and fuses antero-medially with the medial border of the frontal process of maxilla (Figures $4 \mathrm{f}, \mathrm{h} ; 5 \mathrm{l} ; 6 \mathrm{~d}$ ) ${ }^{(23)}$. 

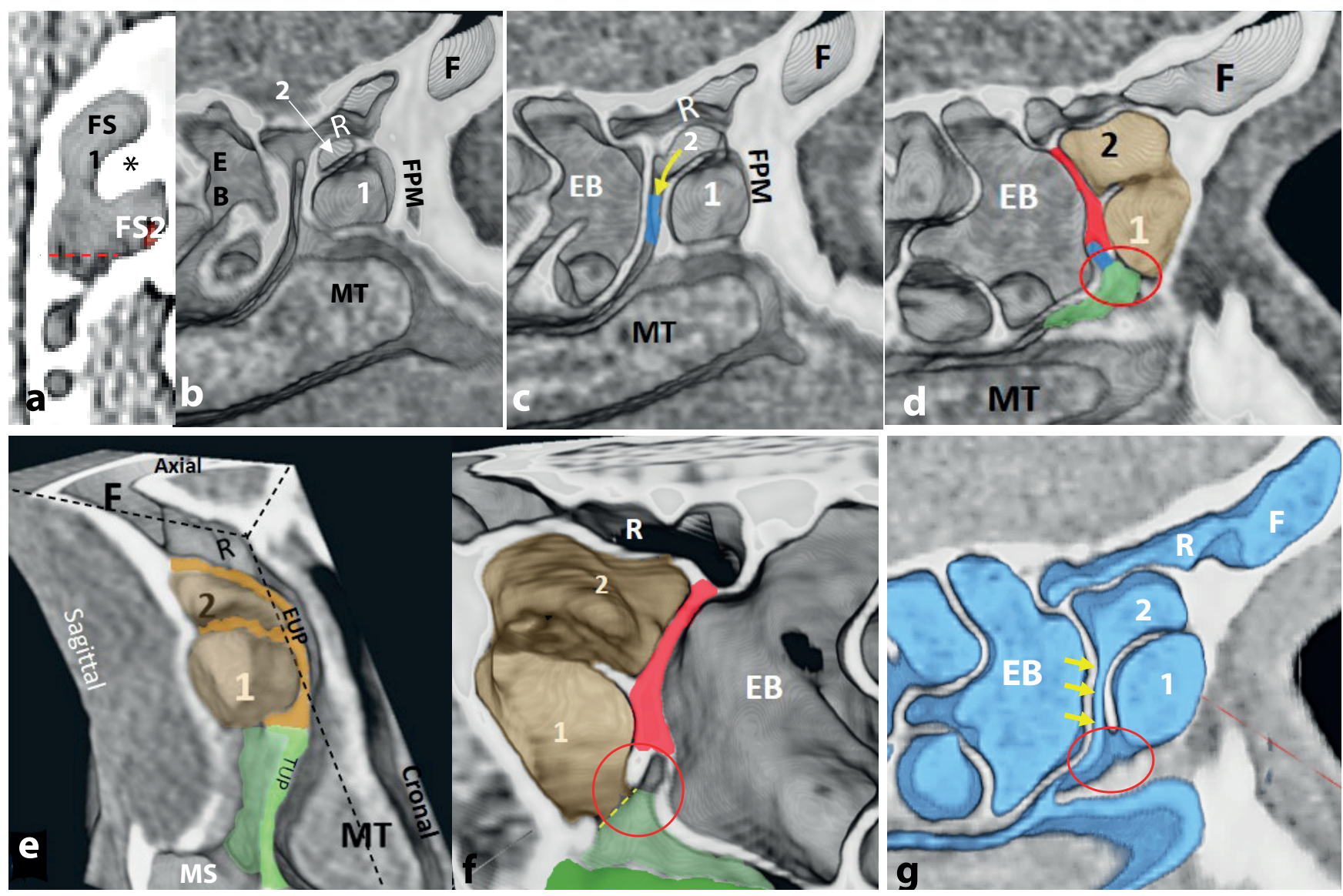

Figure 8. "K1 cell", "Frontal cell, type 1", "Supra agger cell”: described as a single anterior-lateral ethmoid cell, above the ANC, without penetrating the frontal sinus. (a-c), are images in the sagittal plane viewed from medially, with (a) being most medial, and (c) being most lateral. Note two spaces within the EUP bony surround $(1,2)$ with space \#2 pneumatizing into the frontal recess $(\mathrm{R})$ fusing: supero-laterally with the lamina papyracea; posteriorly with the bulla lamella; anteriorly with the Nasal Process of the Frontal Bone (NPFB), and medially with the middle turbinate. Space \#2 "opens" into the superior ethmoid infundibulum fig. (b) (blue outline), (curved yellow arrow). (c-f). (c), a lateral sagittal image; (d) a segmented, and displayed sagittal image viewed from lateral (coronal, axial and sagittal planes shown within dashed black lines) which reveals the continuity of the EUP (gold) and TUP (green) bony framework; (e) a sagittal image viewed from laterally; and (f) a sagittal image viewed from medially displaying the 3 dimensionality of the air within the anterior ethmoid spaces and FSRS. (c-f) reveal the outline of the common lamella (red); the communication of space \#1 with the turbinal infundibulum (light green outline); the communication of space \#2 with the ethmoid infundibulum (yellow arrows) and the inter-communication between the inferior ethmoid infundibulum/turbinal infundibulum/IS-EUP (red oval).

Superiorly, the EUP attaches horizontally along the suture between the frontal bone/frontal process of the maxilla/nasal process of frontal bone (NPFB), creating a horizontal plate, which fuses laterally with the lamina papyracea, and posteriorly with the bulla lamella/common lamella, creating a polyhedral space contained within the EUP, is the Infundibular Space of the Ethmoid Uncinate Process segment (IS-EUP), which is commonly referred to as the Agger Nasi Cell (Figures 4 b, d, e, f, h, j; 5 b-e, g-l; $6 \mathrm{a}, \mathrm{d}-\mathrm{g})$.

Inferiorly at the plane of separation between the IS-EUP and the Turbinal Infundibulum ( $\mathrm{TI}$ ), the polyhedral space narrows to create a "wedge-like" oval or round opening. Notably, the posterior portion of the opening communicates with the inferior Ethmoidal Infundibulum (EI), and the dorsal TI. The antero- central portion of the opening communicates with the $\mathrm{TI}$ and in turn the primary ostium of the maxillary sinus (Figures $4 \mathrm{~h}, \mathrm{j} ; 5 \mathrm{~h}$, l; $6 \mathrm{~d} ; 7$ e).

\section{The common lamella}

Posteriorly, the EUP angles laterally and becomes the anterior surface of the ethmoid infundibulum with simultaneous lateral angulation of the bulla lamella which becomes the posterior surface of the ethmoid infundibulum (Figures $4 \mathrm{~d}, \mathrm{e} ; 5 \mathrm{~b}$ ). The posteriorly angled EUP and anteriorly angled BL fuse to create a common partition/wall/lamella between the IS-EUP and EB which we refer to as the Common Lamella (CL) (Figures 5 c-e, l; 6 g)(55). The Common Lamella's orientation/angulation, as well as its extent, varies considerably. Its medial surface is at the depth 

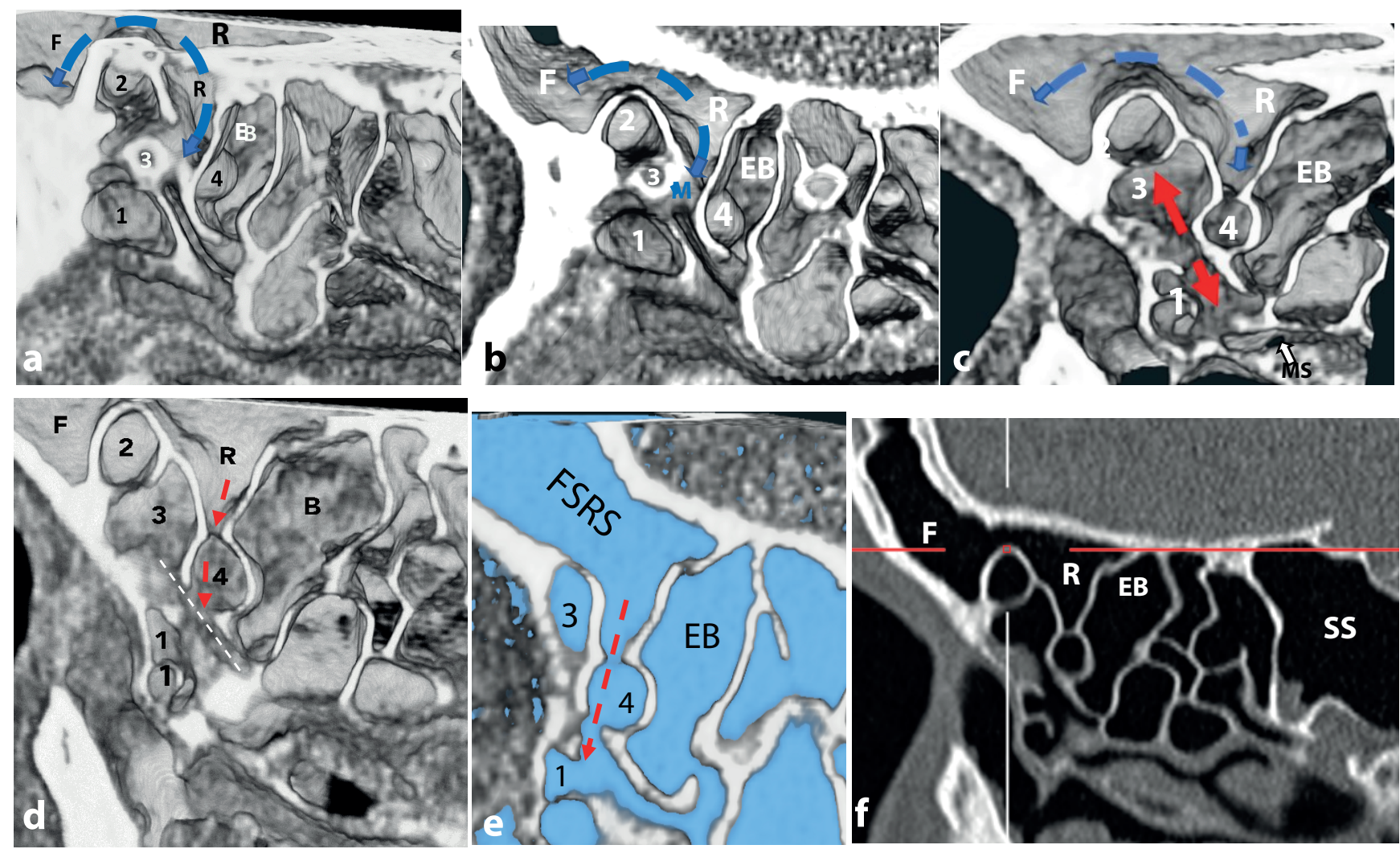

Figure 9. “K2 cell", “Frontal cell type 2": described as two or more anterior ethmoid cells pneumatizing above the ANC. (a-d) are sagittal images viewed from medially, with (a) being most medial and (d) most lateral three (1-3) spaces within the bony perimeter of the ethmoidal uncinate process pneumatizing into the FSRS ( $F$, frontal sinus, and $R$, frontal recess). In ( $a, b)$ a double arrowed blue dashed curved line shows the continuous FSRS, with the posterior arrow showing communication with the middle meatus. Also note, a fourth space in $(c, d)$ created by the outline of the uncinate lamella anteriorly, and the bulla lamella posteriorly, which has a supero-posterolateral communication with the FSRS, and antero-inferiorly a communication with the ethmoid infundibulum (dashed double ended red arrow in (c). (d) a slightly obliqued sagittal image showing the three dimensionality of the airspaces within the anterior ethmoid sinus (blue outlines), with red dashed arrow revealing the communication between the FSRS, through space \#4 to the infundibulum. (f) is a standard sagittal CT image of the same case.

of the ethmoidal infundibulum, and laterally, it fuses with the lamina papyracea (Figures $5 \mathrm{~d}, \mathrm{e}, \mathrm{l} ; 6 \mathrm{f}, \mathrm{g}$ ).

Drainage channels within the anterior ethmoid sinus The ethmoid infundibulum is the conventional term for the space between the entire length of the uncinate process and the ethmoid bulla lamella. It now appears, based upon the 3-DCTSI findings that this space is more complex than we previously realized.

The infundibular space appears to be made up of three interconnected spaces, each named for the uncinate subdivision associated with it:

1. The Ethmoidal Infundibulum (EI) (Figures 7 c, d)- is between the ethmoidal uncinate anteriorly and the bulla lamella, posteriorly. Its medial extent is the hiatus semilunaris, and its depth is the medial surface of the common lamella (CL) (Figures $2 \mathrm{~h}-\mathrm{j} ; 4 \mathrm{~d}, \mathrm{~g} ; 5 ; 7 \mathrm{c}$ ).

2. The turbinal infundibulum (TI) - is defined medially by the turbinal uncinate process and laterally by the medial surface of the maxillary sinus, and lamina papyracea. It extends from the lacrimal bone anteriorly, under the ethmoid bulla to communicate with the middle meatus through the hiatus semilunaris at the posterior fontanelle. This space communicates with the IS-EUP superiorly, with the ethmoidal infundibulum supero-posteriorly and the maxillary sinus inferiorly (Figures 4 b-e; 5, 6, 7).

3. The infundibular space of the ethmoidal uncinate process (IS-EUP), the polyhedral space enclosed by the EUP, described above, inferiorly directly communicates with the TI, and infero-posteriorly with the $\mathrm{El}$, and is currently referred to as the Agger Nasi Cell (ANC) (Figures $4 \mathrm{f}, \mathrm{h}, \mathrm{j} ; 5$ a-e, l; 6 a-e; 7). Our use of the descriptor IS-EUP, is meant to more accurately name the space we currently refer to as the ANC, and avoid the confusing relationship between the ANC and the uncinate process. Given that the IS-EUP space is one and the same as the "agger nasi space", the terms could be used interchangeably with the understanding that both re- 


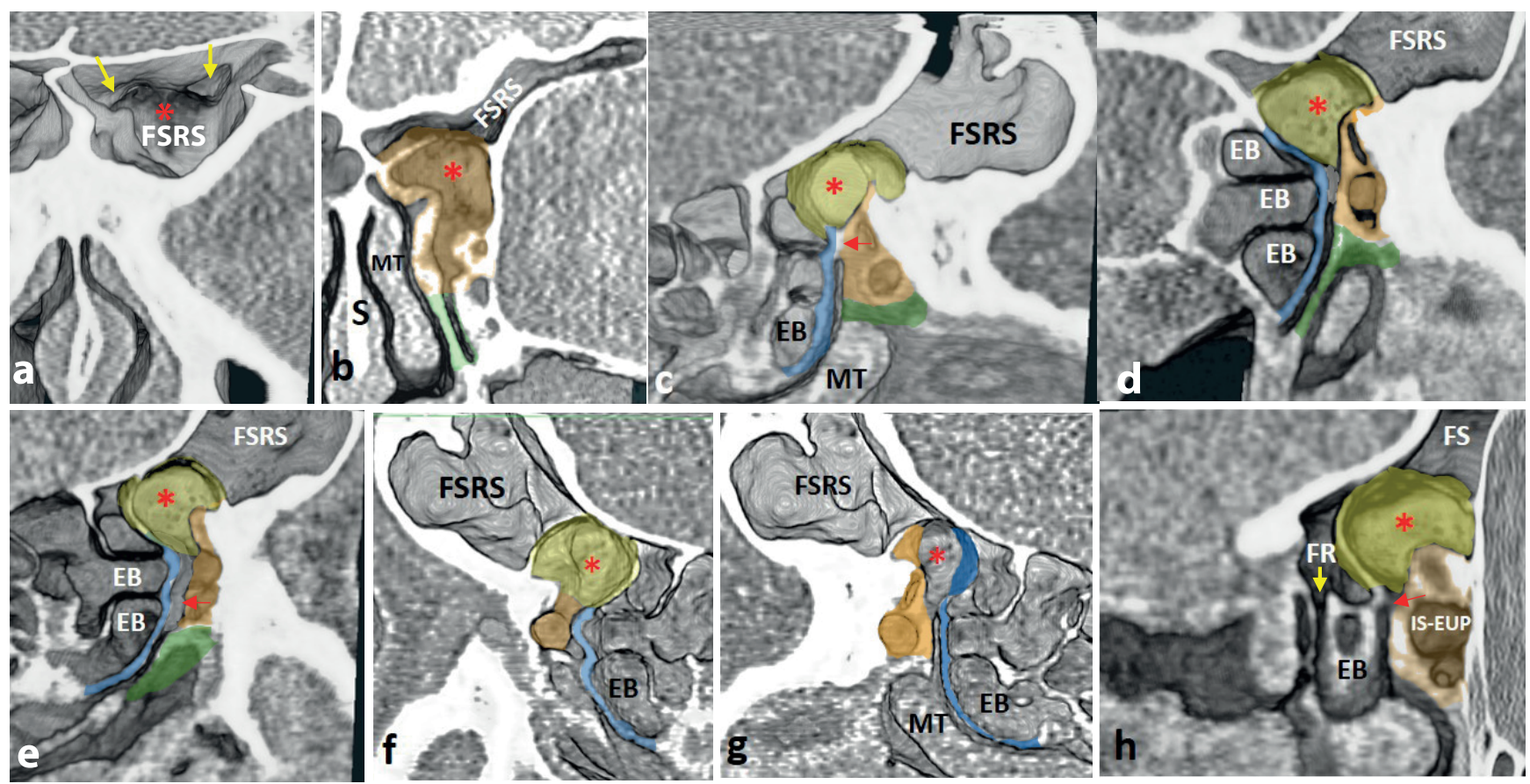

Figure 10."K3 cell", "Frontal cell type 3": a single cell above the ANC, extending from the frontal recess into the frontal sinus with superior wall inserting into the inner surface of the anterior frontal sinus. (a) is a coronal image just posterior to the anterior frontal sinus wall, revealing a "bulging" structure ${ }^{*}$ ) with near occlusion of the Frontal Sinus Recess Space (FSRS): superolateral and superomedial spaces afford communication between the frontal sinus and frontal recess(yellow arrows). (b) is a coronal image revealing that the "bulging structure" represents a pneumatization of the superiorly extending uncinate lamella into the FSRS, fusing medially to the frontal septum, and laterally to the lamina papyracea. On sagittal images (c-e), viewed from medially and noted to extend from medial to lateral reveal a close relationship between the bulla lamella (blue outline), the ethmoid uncinate process (gold coloured structure) and the emerging pneumatized space (greenish/yellow colour) extending into the frontal recess, as well as the posterior frontal sinus space, as it adheres to the posterior floor of the frontal sinus. Sagittal images in (f-h) are viewed from laterally, and specifically in (g) contributions from the uncinate (gold) and bulla lamella (blue) shows their joint "contribution" in the creation of the superiorly extending pneumatized space $\left.{ }^{*}\right)$, which is the terminal ending of the ethmoid infundibulum, and a "terminal recess" space.

fer to the polyhedral space created by the ethmoid Uncnate segment and its fusion with the FPM, LP, BL, and CL.

Superiorly, the ethmoid infundibulum may terminate: 1) into the FSRS (as in this case) (Figures $2 \mathrm{i}, \mathrm{j} ; 5 \mathrm{a}, \mathrm{b} ; 7 \mathrm{~b}-\mathrm{d} ; 11 \mathrm{e}, \mathrm{f}, \mathrm{h}$ ); 2 ) directly into the IS-EUP (Figures $8 \mathrm{~g} ; 9 \mathrm{c}, \mathrm{d} ; 12 \mathrm{c}, \mathrm{d}$ ); 3 ) a space created by the coalescence of the uncinate and bulla lamellae, at or near the skull base (Figures $10 \mathrm{~b}-\mathrm{h}$ ).

\section{The "K 1" / "Type 1 Frontal Cell" (Figure 8)}

The FSRS, has a bony ridge in the floor of the frontal sinus, creating two separate components within the frontal sinus (Figure 8 a). The plane of separation between the frontal sinus and frontal recess is just dorsal to the opening of the more lateral space. There is no evidence of a specific landmark establishing a separation between frontal sinus and frontal recess, and the FSRS is continuous and uninterrupted. The opening of the FSRS is in the postero-medial frontal recess directly into the middle meatus, and indirectly into the ethmoid infundibulum (Figures 8 b, c, e). The EUP bony architecture surrounds two separate infundibular spaces with the more superior space pneumatized into the frontal recess volume, without adhering to the skull base (Figures 8 $b-g)$. The roof of the superior EUP fuses laterally with the lamina papyracea, anteriorly with the NPFB, medially with the middle turbinate, and posteriorly with the superior common lamella at its junction with the bulla lamella. The superior IS-EUP space has a direct individual communication with the superior ethmoid infundibulum (Figure $8 \mathrm{c}$ ).

The inferior IS-EUP space has a direct communication with the TI through an oval opening extending from: anteriorly, at the junction of the lacrimal bone/FPM inferior tip/anterior EUP and lamina papyracea; posteriorly, to the inferior ethmoid infundibulum/common lamella (Figures $8 \mathrm{~d}, \mathrm{~g}$ ).

The TUP visibly, extends posteriorly to the posterior fontanelle (Figures $8 \mathrm{~d}, \mathrm{~g}$ ).

The TI communicates directly with the primary ostium of the maxillary sinus (Figure 8 e).

\section{The "K 2" / "Type 2 frontal cell" (Figure 9)}

The FSRS is a single uninterrupted space posteriorly bordered 


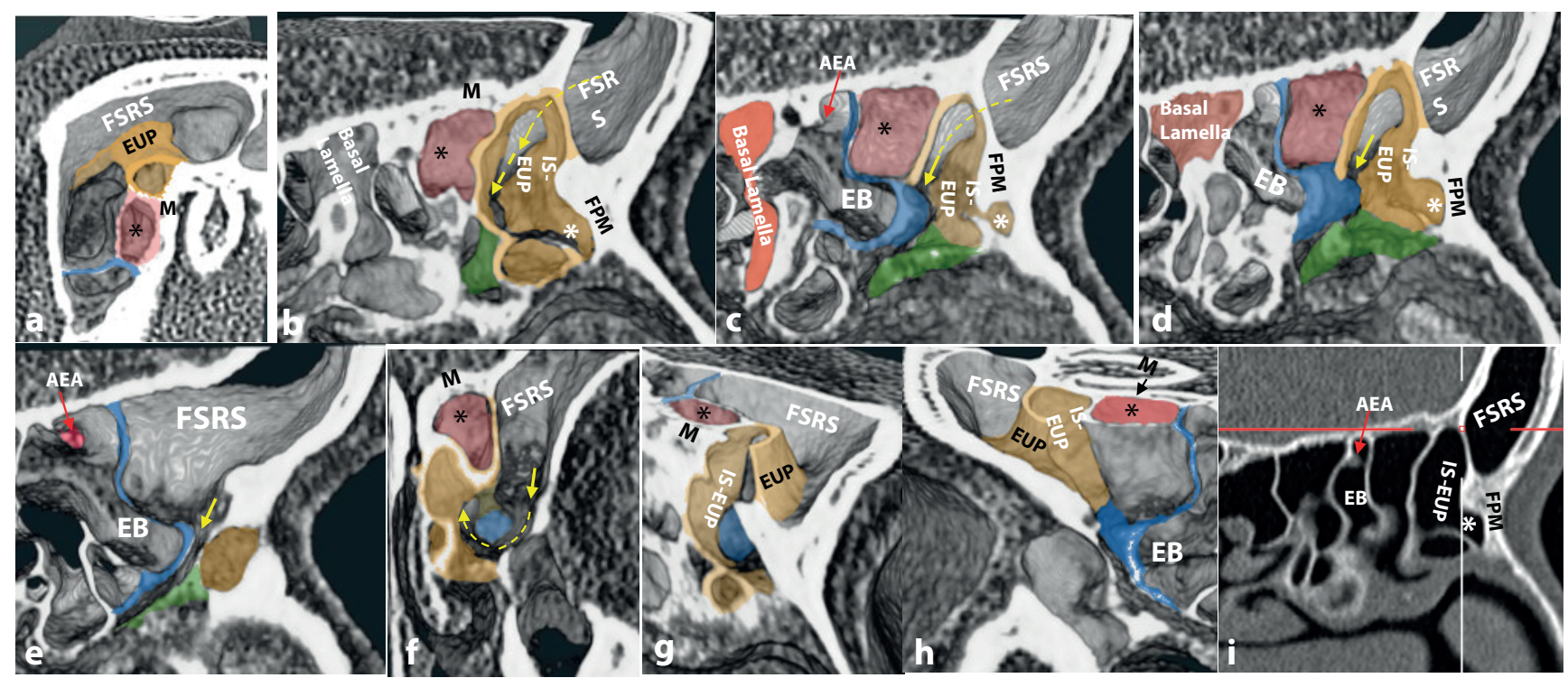

Figure 11. "Variation of K3 cell/Frontal cell type 3": a single cell above the ANC, extending from the frontal recess into the frontal sinus with superior wall extending to skull base, inserting onto the inner surface of the anterior frontal sinus, with prominent inferior extension of the frontal recess floor. (a), is a 3DCTSI axial image of the left frontal sinus viewed from above, showing the EUP adherent medially to the middle turbinate (M), and anteriorly to the inner surface of the anterior frontal bone, "wrapping" posterolateral to the lamina papyracea. There is a space between the EUP and the bulla lamella (blue outline, ${ }^{*}$ ) which is fused to the middle turbinate $(M)$ medially. $(b-d)$ are sagittal images viewed from medially, and progressing from medial to lateral. Note the IS-EUP above the space currently referred to as the ANC, extends superiorly, penetrating the medial frontal recess space, and fusing with the skull base. Its anterior "limb" angles forward to fuse with the floor of the frontal sinus. Also of note is the fact that the frontal recess extends postero-laterally displacing the EUP bony architecture medially so that the superior EUP does not fuse with the lamina papyracea. This in turn is associated with an opening in the lateral wall of the EUP affording a direct communication between frontal recess and IS-EUP (dashed curved yellow arrow). The pink shaded space $\left(^{*}\right)$ is enclosed anteriorly by the uncinate lamella, posteroinferiorly by the bulla lamella and the ethmoid bulla (EB), and superiorly by the skull base. Note that the IS-EUP has a prominent indentation $\left(^{*}\right)$ into the inferior frontal process maxilla (FPM), corresponding to Layton's definition of an ANC. (e) a most lateral sagittal display of the lateral nasal wall, showing the attachment of the bulla lamella (blue outline) to the Lamina Papyracea. Note that in this case the floor of the frontal recess also extends to a segment of the bulla lamella. The opening in the floor of the frontal recess is lateral, adjacent to the lamina papyracea, with direct communication to the infundibulum (yellow arrow). Note location of the anterior ethmoid artery (AEA, red arrow) also shown in $(c, i)$. $(f)$, is an anteriorly obliqued coronal plane showing the anterior blue tip of the bulla lamella as it penetrates the space of the uncinate process. It also shows the semicircular course of the ethmoidal \& turbinal infundibulum, which communicates laterally with the frontal recess opening and medially with the turbinal Infundibulum (curved dashed arrow). 9 (g), anteriorly angled sagittal image viewed from medially and fig. (h)sagittal image viewed from laterally. Both reveal the "pinkish" outlined space, also shown in (a-d), which given its fusion with the middle turbinate $(\mathrm{M})$ either represents an inter-lamellar space or a concha bullosa. Its lateral wall fuses the uncinate and bulla lamella. Note the prominent "gap" in the lateral wall of the EUP in (h), representing the direct communication between the IS-EUP and frontal recess. The posterolateral extension of the inferior EUP adherent to the lamina papyracea representing the additional "segment" completing the floor of the FSRS. (i) is a representative sagittal standard CT image along the medial EUP, similar to (b) showing two separate IS-EUP spaces, however as shown with 3DCTSI these spaces combine/communicate within the bony framework of the EUP.

by the bulla lamella (Figures 9 a-f), medially; by the middle turbinate and the frontal intersinus septum; laterally by the lamina papyracea; superiorly, by the skull base/orbital plate; and inferiorly by the roof of the EUP, which pneumatizes into the frontal recess volume. The superiorly pneumatized EUP extends transversely across and into the floor of the frontal recess and displaces the floor of the frontal recess superiorly, as the indentation into frontal recess space extends from middle turbinate to lamina papyracea. There are two openings affording communication between FSRS and anterior ethmoid: a postero- medial opening into the middle meatus (Figures $9 a, b$ ); and a lateral opening into a space created by the uncinate lamella and bulla lamella (Figures $9 \mathrm{c}$-e). The opening from the frontal recess is into the superior portion of the space, as a second opening is present antero-inferiorly affording communication with the infundibulum (Figures $9 \mathrm{c}-\mathrm{e}$ ). The anterior border of this "common" space spanning between the two openings, represents the common lamella.

The EUP bony architecture surrounds: a single apical space, which communicates postero-medially with the middle meatus; 


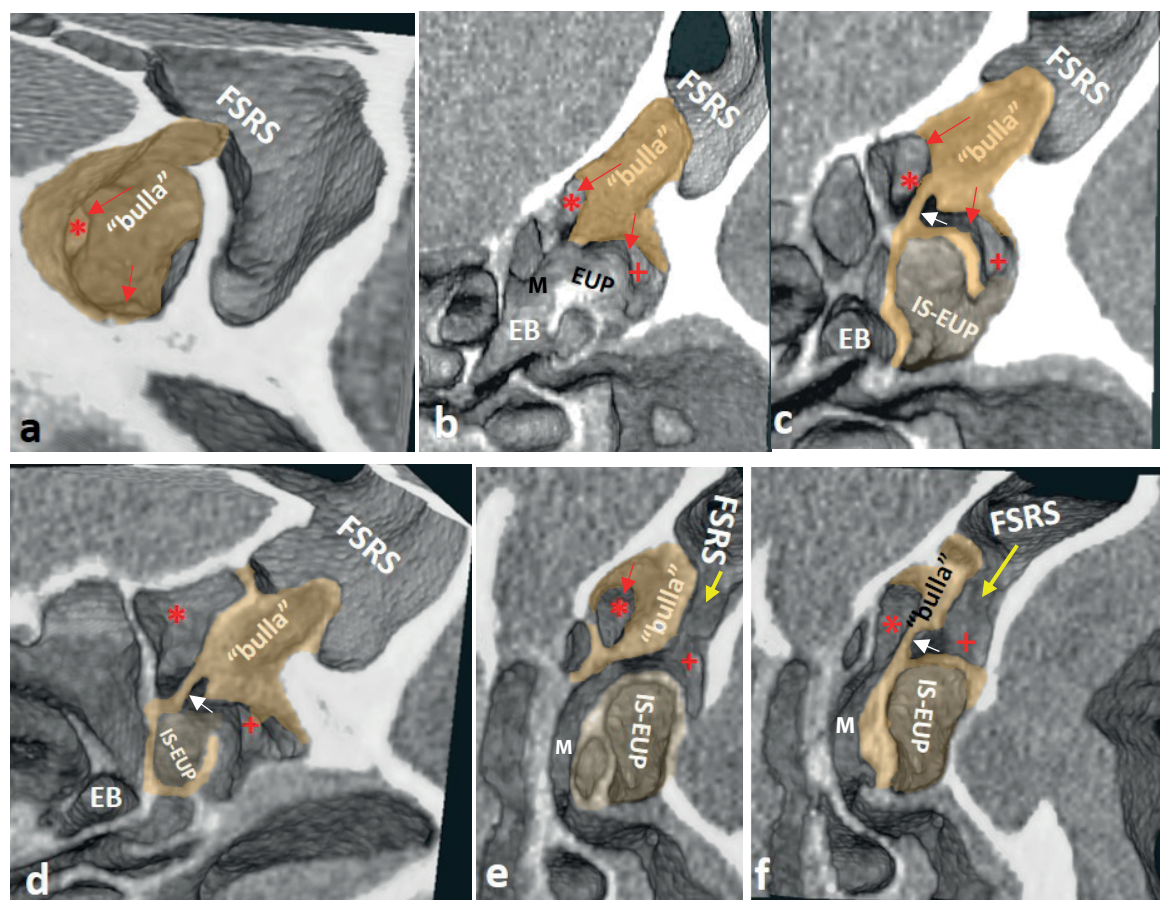

Figure 12. "K4 cell", "Frontal cell type 4": appears as an "air bubble" in the frontal sinus on coronal CT, and looks like a "balloon on a string" on sagittal CT. (a-d), are sagittal images revealing a space which is pneumatized from the antero-superior ethmoid sinus, and penetrates into the medial FSRS. A 2-D coronal image through this cell protruding into the frontal sinus might well appear as an isolated "air bubble" within the frontal sinus. Note that the pneumatized space has a "partial balloon like shape" ("bulla"). In (b-d) it is attached inferiorly to the superiorly extending uncinate lamella (white arrow), arising from the supero-posterior corner of the EUP bony architecture (gold outline). Also note that this short lamella connecting the "bulla" with the EUP bony architecture has the appearance of a "balloon on a string", as previously described. The "bulla", communicates with the middle meatus ( $M$, red asterisk), as well as the IS-EUP ( + ). $(c, d)$ are sagittal images, and $(e, f)$ are coronal images, revealing communication between the FSRS and the middle meatus (M) and IS-EUP (+).

two additional incompletely walled off spaces, which converge to communicate with the Ethmoidal Infundibulum. The TUP is in direct communication with the IS-EUP and the maxillary sinus (Figure $9 \mathrm{c}$ ).

The superior EUP fuses anteriorly with the NPFB, posteriorly with the common lamella (above described), medially with the middle turbinate and laterally with the lamina papyracea.

\section{The "K3" / "Type 3 frontal cell" (Figure 10)}

In this example, an expansile pneumatized space arising from the anterior ethmoid region superiorly displaces the floor and compresses the volume of the anterior frontal recess and posterior frontal sinus. The bony perimeter of the pneumatized volume fuses anteriorly to the posterior floor of the frontal sinus, and the superiorly extending uncinate lamella. Its roof adheres to the FSRS roof, and tapers laterally to fuse with the lamina papyracea and medially to the frontal inter-sinus septum creating a narrow space medially and laterally affording communication between the frontal sinus and the posterior frontal recess spaces. Its posterior rim is continuous with the bulla lamella and common lamella. Medially, the pneumatized space fuses to the frontal inter-sinus septum, and borders the middle meatus
(Figure $10 \mathrm{~b}$ ). The FSRS has a postero-medial opening which communicates with the middle meatus (Figure $10 \mathrm{~h}$ ).

Note that the ethmoid bulla "space" extends anteriorly to narrow the EUP and the TUP. The ethmoid Infundibulum extends superiorly to terminate in a space, which is pneumatized jointly by the bulla and uncinate lamellae (Figures 10 b-h). In effect, the resultant pneumatized space occupying the majority of the frontal recess and the posterior frontal sinus is a "Terminal Recess" in direct communication with the ethmoid infundibulum (Figures $10 \mathrm{~b}, \mathrm{~d}$-h).

\section{Variation of "K3" / "Type 3 frontal cell" (Figure 11)} The FSRS is a continuous and uninterrupted space which antero-medially extends laterally from the frontal sinus septum, to "wrap" around the superiorly extending EUP, and a space between the EUP and the bulla lamella, terminating posteriorly at the bulla lamella (Figure $11 \mathrm{a}$ ). The floor of the frontal recess extends further inferiorly than usual to the infero-laterally extending EUP and bulla lamella. The opening of the frontal recess is antero-lateral directly into the infundibulum, which curves in the shape of a semicircle around the anteriorly extending tip of the ethmoid bulla (Figures $11 \mathrm{e}, \mathrm{f}, \mathrm{h}$ ). 
The EUP is an incompletely enclosed space with the appearance of an ANC present above the TUP (Figure $11 \mathrm{~b}$ ). More laterally, this space combines with a larger superior space. Both spaces are within the EUP enclosure and represent the IS-EUP (Figures $11 \mathrm{c}$, d). Note, that on the standard, more medial, sagittal CT image (Figure $11 \mathrm{i}$ ), the two spaces appear to be separate. The bony perimeter of the EUP enclosing the combined spaces (IS-EUP) extends superiorly to fuse superiorly with the skull base and the middle turbinate medially. At the skull base the bony outline of the EUP assumes a steeple shaped configuration with its anterior attachment extending to the floor of the anterior frontal sinus where it extends postero-laterally to fuse with the lamina papyracea (Figures $11 \mathrm{a}, \mathrm{h}$ ). The postero-lateral extension of the frontal recess narrows the volume of the superior EUP/ IS-EUP and is associated with a "gap/opening" in the lateral bony framework of the EUP which affords a direct communication between the frontal recess and the IS-EUP (Figures 11 $b-d, h)$. The ascending uncinate lamella "wraps around" a space between the uncinate lamella and the bulla lamella. This space is medially bordered by the middle turbinate, and therefore the created space may be considered: a concha bullosa, or an interlamellar space (Figures $11 \mathrm{a}-\mathrm{d}, \mathrm{f}$-h). Nevertheless, it's lateral wall is a continuation of the uncinate lamella which fuses with the bulla lamella infero-posteriorly and may be considered to be a sagittaly oriented common lamella (Figures $11 \mathrm{a}, \mathrm{f}, \mathrm{h}$ ). Note the prominent antero-inferior indentation of the IS-EUP into the frontal process maxilla (FPM) considered by Layton to represent an ANC (Figures $11 \mathrm{~b}-\mathrm{d}$, i) ${ }^{(20)}$.

\section{The "K4" / "Type 4 frontal cell" (Figure 12)}

This entity has had a variety of descriptions, the most common being, that it appears as an isolated "cell" in the frontal sinus on coronal $C T^{(1,2)}$, which may be the case if the entity is viewed with selective coronal images. However, as this example shows that it is a pneumatized/partially pneumatized space with its anteroinferior border adherent to the floor of the frontal sinus and in this case its superior border is adherent to the roof of the frontal sinus/frontal recess. Openings are present primarily along its posterior and/or inferior margins which afford communication with the middle meatus and the IS-EUP (Figures $12 \mathrm{a}$-d).

Lee et al. provide a less commonly mentioned associated finding - the appearance similar to an "air bubble" and" a "balloon on a string" (3). 3DCTSI demonstrates their description, and in this example one notes that the uncinate lamella has a "lamellar extension", which could be construed to look like a "string" connecting the postero-inferior border of the "bullous" pneumatization within the frontal sinus with the uncinate lamella and that the two entities together resemble a "balloon on a string" (Figures $12 \mathrm{c}, \mathrm{d}$ ).

The "bulla" as well as the FSRS communicates with the IS-EUP and the middle meatus (Figure 12).

\section{Discussion}

Our individual and collective understanding of sinus anatomy and its development is based upon anatomic and embryologic investigation by early investigators ${ }^{(14-22)}$, the experience gained from more recent adult dissection ${ }^{(9-13,23-52)}$, and the information provided more recently by sinus CT individual orthogonal and MPR images ${ }^{(1-13,23-34,37-54)}$. Several attempts to show the value of this regional anatomy in $3 \mathrm{D}$ were proposed ${ }^{(49-53)}$.

Recent advances of 3DCTSI and its application to sinus CT anatomy seem to be the most likely solution to an intuitive 3D perception of the complex, varied anatomy of the paranasal sinuses ${ }^{(55,56)}$ (Figure 1). Given the newness of this technology's anatomic display, we selected six examples of the "Classification of Fronto-ethmoid cells" by Kuhn and expanded by Wormald et al., and adopted by Huang et al., Ramakrishnan et al; and Void et al., to illustrate our findings and contrast our observations with those reported in the current literature ${ }^{(1-7)}$. The study focused on the following observations:

Cells vs. spaces within the ethmoid sinuses

Zukerkandl, Seydel, and Van Alyea described the anatomy of the ethmoid sinus as a "labyrinth" enclosed in a "capsule," and that lamellae within the "capsule" served to separate groups of cells, each group retaining its original drainage channels ${ }^{(14-16)}$. Schaeffer, in 1916, concluded that the frontal sinus may originate from "one or more of the cellulae ethmoidales anterior," and was one of the first to refer to the compartments within the anterior ethmoid sinus as "cells" (18). Terrier reported that the ethmoidal compartments had the external appearance of a "centrifugal" arrangement of balloons with proximal ostia in each case, inferring a distinction between the "cellular concept" and the "space concept" (38). Marquez et al., stated that an "air space" must have two features to be defined as an ANC: it has been a cell, which is a sphere-like air space with a drainage ostium smaller than the space diameter ${ }^{(35)}$. Pianta et al. adopted this concept in establishing their $A B C$ classification of the frontal sinus drainage pathway and referred to the compartments within the anterior ethmoid sinus as spaces, not cells ${ }^{(39)}$. Arun et al., stated that "the frontal recess is a three-dimensional space connecting the frontal sinus superiorly with the nasal cavity inferiorly" (40). We realize that the traditionally mentioned anatomical concept of "ethmoidal cells" represents a simplified observational explanation. In essence, what we currently call "ethmoidal cells" are "spaces" with slit-like or round openings, varying in size and in the traditional sense, are not "ostia." Each space individually, or in combination with other spaces, communicates with the infundibulum, which, in turn, communicates with the middle meatus, thus allowing air exchange and mucociliary clearance to occur (Figure 7). 
The frontal sinus recess space (FSRS) nomenclature

Schaeffer states that the middle meatus extends ventro-cephalically, where it becomes the 'anlage' of the frontal recess and represents the first step in the formation of the frontal sinus ${ }^{(18)}$. Lund et.al. reported that the frontal recess "is the most anterosuperior part of the ethmoid," and is synonymous with the "frontal sinus drainage pathway." Furthermore, they state that the terms "frontal sinus" and "frontal recess" refer to two separate entities and that the opening of the frontal sinus is best defined on a sagittal CT section; and the contours between the frontal sinus and frontal recess form an hourglass shape, with the narrowest point at the frontal sinus opening. Furthermore, they state that then frontal recess "is a term that has been defined in various ways over many decades and remains disputed" (41).

Daniels et al. described the drainage of the frontal sinus through the frontal recess to be complex, as it is altered by air cells within the frontal recess and the varied attachment of the uncinate process ${ }^{(42)}$. Stammberger et al. described the opening of the frontal sinus to be an hourglass-like narrowing formed between the frontal sinus and the frontal recess, and that the frontal recess has the appearance of an inverted funnel-shaped structure, synonymous with the frontal sinus drainage pathway ${ }^{(10-12)}$. Wormald et al. described the frontal ostium as being in a plane that is anteriorly defined by the frontal sinus beak, and posteriorly by the skull base ${ }^{(24)}$.

Evaluation with 3DCTSI shows the frontal sinus and frontal recess to be a united and continuous irregular volume, with no evidence of specific anatomic landmarks, which create an hourglass-like narrowing that separate the two spaces. The concept of the hourglass-shaped narrowing is largely based on the information provided by CT MPR images.

The frontal sinus and the frontal recess (the latter understood here as the whole anterior-superior part of the unilateral anterior ethmoid, incorporating specific cells or spaces) is comprised of two confluent spaces. In a variety of cases, the impression of a defined "narrow-pass" between the two cavities is envisioned. However, irrespective to the relative expansion of the anteriorsuperior frontal sinus and the obvious narrowing as the frontal sinus space "joins" the frontal recess space, a defined anatomic landmark to precisely locate an "opening" / "ostium" / or plane of separation between these two spaces is absent. Contrasting views in the literature are based on virtual geometric calculations and illustrations disregarding 3D anatomy ${ }^{(24-26,39)}$. As such the combined uninterrupted space is more accurately referred to as the Frontal Sinus/Recess Space (FSRS).

\section{The uncinate process anatomy}

Regarding the Uncinate Process anatomy, confusion has been disseminated by a multitude of publications. The EPOS ma- nuscript describes the uncinate process as a single structure without subdivisions/parts ${ }^{(43)}$. Reports state that, anteriorly, it may have a common attachment with the medial surface of the Agger Nasi Cell (ANC), implying that there would be three layers of tissue medial to the "cell/space." In actuality, the ANC is created by the fusion of two structures: the middle turbinate, most medially; and the antero-superior EUP, which is the medial wall of the IS-EUP, without an additional "wall" belonging to the ANC as inferred by the definition and illustration provided by Farneti et al. ${ }^{(46)}$.

Wake et al., Wormald, Shamas et al., and Netto et al. concluded that the uncinate is divided into three parts: the middle portion of the uncinate process attaches to the lacrimal bone and lamina papyracea, and the posterior horizontal portion attaches to the ethmoidal process of the inferior turbinate and palatine bone. The superior portion of the uncinate extends to a varying degree into the frontal recess ${ }^{(25,30,32,33)}$. Unfortunately, these reports do not describe the planes of separation between their proposed subdivisions. We are in agreement with their description of the horizontal segment, which we call the TUP, and we also agree with their description of the superior segment, which we call the EUP. We do, however, take issue with their description of the middle portion, stated to be the attachment of the uncinate process to the lacrimal bone and the lamina papyracea. This focal anatomic landmark, however, including the fusion at the inferior tip of the FPM to lacrimal bone and lamina papyracea is the anterior focal point of the plane of separation between the IS-EUP and the TI. The plane extends posteriorly to the inferior common lamella/inferior ethmoid infundibulum/posterior rim of the opening affording communication between the IS-EUP above the plane, and TI below the plane. This plane is undefined in previous manuscripts.

The uncinate process has been described to be intimately related to the middle turbinate, frontal process of the maxilla, frontal recess, frontal sinus, ethmoid bulla, bulla lamella, common lamella, lamina papyracea, lacrimal bone, inferior turbinate, and palatine bone. The superior attachment of the EUP has received considerable attention, revealing a broad variability ${ }^{(41-44)}$. In 2006, Ercan et al. found that "a significant relationship between the presence of the ANC and superior insertion types of the UP was not found, and that further studies are needed to investigate the relationship" (48). Our Table 1, addresses this issue and describes the varied superior attachment in our selected cases as demonstrated with 3 DCTSI ${ }^{(39-42)}$. A more extensive evaluation of the superior attachment of the EUP will follow.

The uncinate process is said to be related to the Agger Nasi cell; however, distinct boundaries between the two structures have not as yet been defined ${ }^{(34,48,53)}$. Wormald states: "confusion 
still exists about how this upward continuation of the uncinate relates to the Agger Nasi and if present, the frontal ethmoid cells" (24,25,46). Wormald and Kim et al. tried to resolve the "confusion" with the following statement: "Most of the agger nasi cell is anterior to the uncinate, but the posterior half of the agger nasi cell has an intimate relationship with the upward extension of the uncinate process" ${ }^{\prime 24,46)}$. Nevertheless, a distinction between these two structures remains without explanation. Similarly, Zhang et al. failed to define a distinct separation between the two structures ${ }^{(47)}$. Layton's opinion on the subject is: "In this collection I have only classed as agger nasi cells those which hollow out to some extent the nasal process of the superior maxilla" (20). This definition, however, needs to consider the fact that, in virtually every case, we encountered the pneumatization into the frontal process of the maxilla, it was in communication with the IS-EUP (Figure 11). Even though the medial surface of the ANC is the "mound", it is the EUP that lines the medial surface of the polyhedral space, currently referred to as the ANC, and therefore would more accurately be named the Infundibular Space of the Ethmoid Uncinate Process (IS-EUP). The superior attachment of the superior Ethmoid Uncinate Process segment in the six cases demonstrated in this manuscript are presented in Table 2.

Our detailed description of the Uncinate Process segments and particularly the description of the polyhedral shaped IS-EUP, is meant to clarify the origin of the polyhedral space commonly referred to as the ANC, and clarify the confusion concerning the relationship between the ANC and the uncinate process. Given that the IS-EUP space is one and the same as the "agger nasi space", the terms could be used interchangeably with the understanding that both refer to the polyhedral space created by the ethmoid Uncinate segment and its fusion with the FPM, $\mathrm{LP}, \mathrm{BL}$, and $\mathrm{CL}$.

\section{The infundibulum}

The tortuous course of the infundibulum, its complex association with the uncinate process and the ethmoidal bulla, and its pronounced segmentation by CT MPR images, are all part of the challenge in understanding its full extent and relationship with its neighbouring spaces.

Both Zukerkandl and Schaeffer considered the infundibulum to be the "conduit" between the FSRS, the anterior ethmoid spaces, and the maxillary sinus ${ }^{(15,18)}$.

3DCTSI evaluation reveals the following intercommunications provided by the infundibulum:

1. The FSRS communicates with the anterior ethmoid sinus directly into the middle meatus, directly or indirectly into the El and rarely directly into the IS-EUP.

2. The IS-EUP opens directly into the El and the TI.
Table 1. Key to abbreviations.

\begin{tabular}{|ll|}
\hline Abbreviations & Definitions \\
\hline ANC & AggerNasi cell \\
\hline BL & Bulla Lamella \\
\hline CT & X-ray Computed Tomography \\
\hline CTMPR & X-ray Computed Tomography with Multiplanar \\
\hline BDCTSI & Reconstructions \\
\hline EUP & $\begin{array}{l}\text { Three-D. Computed Tomography with Stereosco- } \\
\text { pic Imaging }\end{array}$ \\
\hline FESS & Ethmoidal Uncinate Process \\
\hline FSRS & Functional Endoscopic Sinus Surgery \\
\hline EI & Frontal Sinus/Recess Space \\
\hline ET & Ethmoidal Infundibulum \\
\hline FPM & Embryonic Ethmo-Turbinal \\
\hline FSRS & Frontal Process Maxilla \\
\hline IS-EUP & Frontal Sinus/Recess Space \\
\hline MMT & Infundibular Space of the Ethmoidal Uncinate \\
\hline TUP & Process \\
\hline TI & Middle Meatal Turbinals \\
\hline
\end{tabular}

3. The TI communicates with the IS-EUP superiorly, the El superiorly-posteriorly, and with the middle meatus postero-laterally, as its free margin extends to the posterior fontanelle under the ethmoidal bulla. Inferiorly, it communicates directly with the maxillary sinus.

\section{Conclusions}

As the potential for minimally invasive surgery grows, increased recognition of the sinus anatomy and its common variations becomes increasingly important, and 3DCTSI provides the opportunity to clearly the anatomy and variations which previously, were not appreciated.We present our observations of the normal 3D anatomy as displayed with 3DCTSI of the anterior ethmoid and fronto-ethmoidal transition zone in six exemplary cases, representative of the "Classification of the Fronto-ethmoidal cells" by Kuhn and expanded by Wormald et al., and adopted by Huang et al.; Ramakrishnan et al; and Void et al. (1-7). The cases are pathology-free. These cases demonstrate the common anatomic variations within the frontal and anterior ethmoid structures, spaces, and drainage pathways. An attempt to clarify the confusion relating to the association between the ANC and the Ethmoid Uncinate Process segment is provided. The spaces appearing to be within the frontal recess and frontal sinus are pneumatized spaces originating from the anterior ethmoid. Also of note are the following observations:

1. The compartments within the anterior ethmoid sinus, 
Table 2. Multiplicity of superior attachment zones of the ethmoidal uncinate process.

\begin{tabular}{|c|c|c|c|c|c|c|c|c|}
\hline \multirow{2}{*}{$\begin{array}{l}\text { Fronto-ethmoidal cell-type } \\
\text { acc. to Bent et al. (1994) }\end{array}$} & \multicolumn{8}{|c|}{ Attachment Zones } \\
\hline & Lamina P & Mid. T & Bu La & NPFB & Com La & Fr ISS & Sk B & Fr S Floor \\
\hline ANC (no type) & $\mathrm{X}$ & $\mathrm{X}$ & $x$ & $x$ & $\mathrm{x}$ & & & \\
\hline Type 1 FC & $\mathrm{x}$ & $\mathrm{X}$ & $x$ & $X$ & $\mathrm{X}$ & & & \\
\hline Type 2 FC & $\mathrm{x}$ & $\mathrm{x}$ & & $\mathrm{X}$ & $\mathrm{X}$ & & & \\
\hline Type 3 FC & $x$ & & $x$ & $x$ & $\mathrm{x}$ & $x$ & $x$ & $x$ \\
\hline Variation Type 3 FC & & $x$ & & & $x$ & & $x$ & $x$ \\
\hline Type 4 FC & $\mathrm{X}$ & $\mathrm{X}$ & & $x$ & $\mathrm{X}$ & $x$ & $\mathrm{X}$ & $\mathrm{X}$ \\
\hline
\end{tabular}

Agger Nasi Cell (ANC); Frontal Cell (FC); Lamina Papyracea (Lamina P); Middle Turbinate (Mid T); Bulla Lamella (Bu La); Nasal Process Frontal Bone (NPFB); Common Lamella (Com La;) Frontal Intersinus Septum (Fr ISS); Skull Base (SK B); Frontal Sinus Floor (Fr S Floor).

previously referred to as "cells," are, in essence, spaces with an opening, which, if unaffected by pathology, afford air exchange and mucociliary clearance.

2. The frontal sinus and frontal recess are a united and uninterrupted three-dimensional cuboidal space, the Frontal Sinus/Recess Space (FSRS), without identifiable landmarks showing the separation between Frontal Sinus and Frontal recess. A narrowing between the two spaces is occasionally present, however, its location varies. The opening, "draining" the FSRS is primarily directly into the middle meatus, and, less frequently directly into the ethmoidal infundibulum, and even less frequently directly into the IS-EUP.

3. The uncinate process has two structural segments: the Ethmoidal Uncinate Process segment (EUP), creating a polyhedral shaped pneumatized space, the Infundibular Space of the Ethmoid Uncinate Process segment (IS-EUP); and the Turbinal Uncinate Process segment (TUP), creating a vertically shaped space, the Turbinal Infundibulum (TI).

4. The middle meatus and the ethmoidal and turbinal infundibular channels are the principal draining channels that enable air exchange and mucociliary drainage of the anterior ethmoid spaces, the frontal sinus and the maxillary sinus.

New anatomic details are described and nomenclature created to fit these observations. Our objective is to clarify the confusion resulting from previous less-than-optimal imaging technology and provide an introduction to an improved understanding of the frontal sinus outflow tract and anterior ethmoid spaces, with implications for facilitating surgery and fostering future innovative approaches, as we are repeatedly reminded that understanding the anatomy of this area directly influences the surgical success.

\section{Acknowledgments}

The project exploring the advantages of 3DCTSI for the evaluation of the nasal cavity and paranasal sinuses was initiated in 2017 with the aid and inspiration of Heinz Stammberger. Extensive discussions, and a few initial publications followed as we pursued our "re-education," and prepared for a more substantial publication(s). Unfortunately, our friend passed away unexpectedly and could not participate in this publication. His friendship, and the sharing of his knowledge, have been invaluable to us and will continue to be an inspiration in our work as it is carried forward!

We thank our consultants: C. Bachert, P. Castelnuovo, A. Lane, A. Leunig, A. Lopatin, V. Lund, S. Marquez, and J. Pallanch and appreciate their availability to address and assist in clarifying our observations.

\section{Authorship contribution}

SJZ, FAK wrote and edited the manuscript; WH, DK, NJL contributed to the writing and addressed anatomic detail where clarity was needed; MS assisted in creating the needed images.

\section{Conflict of interest}

DK is a consultant for Medtronic and Fiagon companies. W Hosemann is a consultant for Karl Storz. The other authors have no conflict of interest.

\section{Funding}

None

\section{Consent for publication}

Not applicable

\section{Availability of data and materials}

Not applicable. 


\section{References}

1. Kuhn F. Chronic frontal sinusitis: the endoscopic frontal recess approach. Oper Tech Otolaryngology Head Neck Surg. 1996;(7):222-229.

2. Bent JP, Cuilty-Siller C, Kuhn FA, The frontal cell as a cause of frontal sinus obstruction. Am J Rhinology. 1994;8(4):185-191.

3. Lee WT, Kuhn FA, Citardi MJ. 3D com puted tomographic analysis of frontal recess anatomy in patients without frontal sinusitis. Otolaryngol Head Neck Surg 2004;131(3):164-173

4. Wormld PJ, Hosemann W, Callejas C, et al.The International Frontal Sinus Anatomy Classification (IFAC) and Classification of the Extent of Endoscopic Frontal Sinus Surgery (FESS). Int Forum Allergy Rhinol. 2016;6(6): 677-696.

5. Ramakrishnan Y, Zammit-Maempel I, Jones NS, Carrie S. Paranasal sinus computed tomography anatomy: a surgeon's perspective. Journal Laryngol Otol. 2011;(125):11411147

6. Huang BY, Lloyd KM, DelGaudio JM, Jablonowski E, et al. Failed Endoscopic Sinus Surgery: Spectrum of CT Findings in the Frontal Recess. Radiographics. 2009 JanFeb;29(1):177-195.

7. Void $S$, et al. An imaging checklist for preFESS CT: framing a surgically relevant report. Clin Radiol. 2011;(66):459-470

8. Zinreich SJ, Kennedy DW, Rosenbaum $A E$, et al. Paranasal sinuses: CT imaging requirements for endoscopic sinus surgery. Radiology. 1987;(163):769-75.

9. Kennedy DW, Zinreich SJ. The functional endoscopic approach to inflammatory sinus disease: current perspective and technique modifications. Am J Rhinology. 1988;(2):89-96.

10. Stammberger $H$, Posawetz W. Functional endoscopic sinus surgery. Concept, indications and results of the Messerklinger technique. Eur Arch Otorhinolaryngology. 1990;247(2):63-76.

11. Stammberger $H$. The Messerklinger technique. In: Stammberger $\mathrm{H}$, editor. Functional Endoscopic Sinus Surgery. Philadelphia: BC Deckker;1991.

12. Stammberger HR, Kennedy DW; Anatomic Terminology Group. Paranasal sinuses: anatomic terminology and nomenclature. Ann Otolaryngol Rhinol Laryngol Suppl. 1995 Oct;(167):7-16.

13. Kennedy DW, Senior BA. Endoscopic sinus surgery: a review. Otolaryngology Clin NorthAm. 1997;(30):313-30.

14. Killian G, Zur Anatomie der Nase menschlicher Embryonen. Arch. f. Rhinol. u. Laryngol. 1895-1896;(2): 3-4.

15. Zuckerkandl E. Normale und pathologische Anatomie der Nasenhöhle und ihrer pneumatischen Anhänge. Braumüller. Vienna 1882

16. Seydel O, Über die Nasenhöhle der höheren Säugetiere und des Menschen. Morphol Jahrb. 1891(17):44-99.
17. Onodi A. Die Nasenhöhle und ihre Nebenhöhlen. Hölder. Vienna 1893.

18. Schaeffer JP. The genesis, development and adult anatomy of the nasofrontal region in man. Am J Anatomy. 1916;(20):125-146.

19. Mosher HP. The applied anatomy and the intra-nasal surgery of the ethmoidal labyrinth. Laryngoscope. 1913;(9):881-907.

20. Layton TB. Catalogue of the Onodi Collection, in the Royal College of Surgeons of England. Published in conjunction with the Royal College of Surgeons of England by the Journal of Otology. London: Headly Brothers.1934.

21. Kasper K. Nasofrontal Connections. Arch Otolaryngol. 1936;(23):322-43.

22. Van Alyea O.E., The Ethmoid Labyrinth, Arch Otolaryngol. 1939 June;(29): 881-902.

23. Kennedy DW, Bolger WE, Zinreich SJ Diseases of the sinuses - diagnosis and management. BC Decker 2001:1-11.

24. Wormald PJ. The agger nasi cell: the key to understanding the anatomy of the frontal recess. Otolaryngol Head Neck Surg. 2003;(129):497-507.

25. Wormald PJ. Endoscopic sinus surgery three dimensional reconstruction and surgical technique. 2nd ed.New York: Thieme medical Publishers; 2008.

26. Park SS, yoon BN, Cho KS, Roh $\mathrm{HJ}$ Pneumatization Pattern of the Frontal Recess: Relationship of the Anterior-toposterior Length of Frontal Isthmus and/ or Frontal Recess with the volume of Agger Nasi Cell. Clinical and Experimental Otorhinolaryngology. 2010 June;3(2):76-83.

27. Landsberg R, Friedman M. A computerassisted anatomical study of the nasofrontal region. Laryngoscope. 2001 Dec;111(12):2125-30.

28. Mahmutoğlu AS, Çelebi I, Akdana B, et al Computed tomographic analysis of frontal sinus drainage pathway variations and frontal rhinosinusitis. J Craniofac Surg. 2015 Jan;26(1):87-90

29. Yoon JH, Kim KS, Jung DH, et al. Fontanelle and uncinate process in the lateral wal of the human nasal cavity. Laryngoscope. 2000 Feb;(110):281-5.

30. Wake M, Takeno S, Hawke M. The uncinate process: a histological and morphological study. Laryngoscope. 1994;(104):364-9.

31. Isobe M, Murakami G, Kataura A. Variations of the uncinate process of the lateral nasal wall with clinical implications. Clin Anat. 1998:11(5):295-303

32. Shamas PN, Wormald PJ, Selva D: Anatomical landmarks of the lateral nasal wall: implications for endonasal lacrimal surgery. Curr Opin Ophthalmology. 2015;(26):408-415.

33. Netto B, Piltcher OB, Meotti CD, Lemieszek J, Isolan GR. Computed tomography imaging study of the superior attachment of the uncinate process. Rhinology. 2015:53(2):187-191.

34. Soyka MB, Treumann T, Schlegel CT. The Agger nasi cell and uncinate process, the keys to proper access to the nasolacrimal drainage system. Rhinology, 2010 Sept;48(3):364-7

35. Messerklinger W. Messerklinger W. Die Rolle der lateralen Nasenwand in der Pathogenese, Diagnose und Therapie der rezidivierenden und chronischen Rhinosinusitis [Role of the lateral nasal wall in the pathogenesis, diagnosis and therapy of recurrent and chronic rhinosinusitis]. Laryngol Rhinol Otol (Stuttg). 1987;66(6):293-299.

36. Wigand ME. Wigand ME. Endoskopische Chirurgie der Nasennebenhöhlen und der vorderen Schädelbasis. Thieme. Stuttgart 1989.

37. Márquez S, Tessema B, Clement PA, Schaefer SD. Development of the ethmoid sinus and extramural migration: the anatomical basis of this paranasal sinus. Anatomic Rec 2008;291(11):1535-53

38. Hosemann W, Draf C. Danger points, complications and medico-legal aspects in endoscopic sinus surgery. GMS Current Topics in Otorhinolaryngology - Head Neck Surgery. 2013;(12):1-61.

39. Kew J, Rees G, Close D, Sdralis T, Sebben $R$ Wormald PJ. Multiplanar reconstructed $\mathrm{CT}$ images improve depiction and understanding of the anatomy of the frontal sinus and recess. Am J Rhinology. 2002;(16):119-123.

40. Terrier F, Terrier G, Rufenacht D, Friedrich JP, Weber W. Die Anatomie der Siebbeinregion: topographische, radiologische und endoscopische Leitstrukturen. Therapeutische Umschau/Revue therapeutique. 1987;(2):75-85.

41. 41. Pianta L, Ferrari M, Schreiber A, et al., Agger-bullar classification (ABC) of the frontal sinus drainage pathway: validation in a preclinical setting. Int Forum Allergy Rhinol. 2016: (6):981-989

42. Arun G, Sanu PM, Mohan M, Khizer HA M, Thampy AS. Anatomical variations in superior attachment of uncinated process and localization of frontal sinus outflow tract. Int J Otorhinolaryngology Head Neck Surgery. 2017;3(2):176-179.

43. Lund VJ, Stammberger H, Fokkens WJ, et al. A. European position paper on the anatomical terminology of the internal nose and paranasal sinuses. Rhinology Suppl. 2014 Mar;(24):1-34

44. Daniels DL, Mafee MF, Smith MM et al. The frontal sinus drainage pathway and related structures. AJNR Am J Neuroradiol. 2003 Sep;24(8):1618-27

45. Isobe M, Murakami G, Kataura A. Variations of the Uncinate Process of the Lateral Nasal Wall with Clinical Implications. Clinical Anatomy. 1988;(11):295-303.

46. Kim KS, Kim HU, Chung IH, Lee JG, Park IY, Yoon JH. Surgical anatomy of the nasofrontal duct: anatomical and computed tomographic analysis. Laryngoscope. 2001 Apr;(111):603-8.

47. Zhang L, Han D, Ge W, et al.. Anatomical and computed tomographic analysis of the 
interaction between the uncinate process and the agger nasi cell. Acta Otolaryngol. 2006 Aug;126(8):845-52.

48. Ercan I, Cakir BO, Sayin I, Başak M, Turgut S Relationship between the superior attachment type of uncinate process and presence of agger nasi cell: a computer-assisted anatomic study. Otolaryngology Head Neck Surg. 2006 Jun;(134(6)):1010-4

49. Rusu MC, Sava CJ, Ilie AC, Săndulescu M, Dincă D. Agger Nasi Cells Versus Lacrimal Cells and Uncinate Bullae in Cone-Beam Computed Tomography. Ear Nose Throat J. 2019 Apr;(23):1-6

50. Isaacs SJ, Goyal P. Comparison between three-dimensional and triplanar computed tomography imaging of the frontal recess. Am J Rhinol Allergy. 2009;(23):502-505.

51. Wormald PJ. Three-dimensional building block approach to understanding the anatomy of the frontal recess and frontal sinus. Oper Tech Otolaryngol. 2006;(17):2-5.

52. Thomas L, Pallanch JF. Three-dimensional CT reconstruction and virtual endoscopic study of the ostial orientations of the frontal recess. Am J Rhinology Allergy.
$2010 \cdot 24(5) \cdot 378-384$

53. Farneti P, Riboldi A, Sciarretta $V$, Piccin $O$, Tarchini P, Pasquini E. Usefulness of threedimensional computed tomographic anatomy in endoscopic frontal recess surgery. Surgical Radiologic Anat. 2017 Feb;39(2):161-168

54. Cohen O, Adi M, Shapira-Galitz Y, Halperin D, Warman M. Anatomic variations of the paranasal sinuses in the general pediatric population. Rhinology. 2019;57(3):206-12.

55. Andrianakis A, Tomazic PV, Wolf A, et al. Optico-carotid recess and anterior clinoid process pneumatization - proposal for a novel classification and unified terminology: an anatomic and radiologic study. Rhinology. 2019;57(6):444-50.

56. Zinreich SJ, Stammberger H, Bolger W Solaiyappan M, Ishii M. Advanced CT imaging demonstrating the bulla lamella and the basal lamella of the middle turbinate as endoscopic landmarks for the anterior ethmoid artery, Rhinology Online. 2019;(2): $32-43$.

57. Bolger WE, Stammberger H, Ishii M, Ponikau J, Solaiyappan M, Zinreich SJ. The Anterior
Ethmoidal "Genu": A Newly Appreciated Anatomic Landmark for Endoscopic Sinus Surgery. Clin Anat. 2019;32(4)45r 5 t:534540.

\section{S. James Zinreich, MD}

Prof. Emeritus,

Radiology, and

Otorhinolaryngology Head and Neck

Surgery

The Johns Hopkins Medical Institu-

tions

Baltimore, MD 21287

USA

Tel: +1-410-804-5054

E-mail: sjzinreich@jhmi.edu

ISSN: 2589-5613 / @2020 The Author(s). This work is licensed under a Creative Commons Attribution 4.0 International License. The images or other third party material in this article are included in the article's Creative Commons license, unless indicated otherwise in the credit line; if the material is not included under the Creative Commons license, users will need to obtain permission from the license holder to reproduce the material. To view a copy of this license, visit http://creativecommons.org/ licenses/by/4.0/ 